\title{
Loss of life expectancy due to respiratory infectious diseases: findings from the global burden of disease study in 195 countries and territories 1990-2017
}

\author{
Guogui Huang ${ }^{1,2}$ (D) Fei Guo ${ }^{3}$ (D)
}

Accepted: 24 May 2021 / Published online: 7 February 2022

(c) The Author(s), under exclusive licence to Springer Nature B.V. 2022

\begin{abstract}
Understanding of the patterns of and changes in mortality from respiratory infectious diseases (RID) and its contribution to loss of life expectancy (LE) is inadequate in the existing literature. With rapid sociodemographic changes globally, and the current COVID-19 pandemic, it is timely to revisit the disease burden of RID. Using the approaches of life table and cause-eliminated life table based on data from the Global Burden of Disease Study (GBD), the study analyses loss of LE due to RID in 195 countries/territories and its changes during the period 1990-2017. Results indicate that loss of LE due to RID stood at 1.29 years globally in 2017 globally and varied widely by age, gender, and geographic location, with men, elderly people, and populations in middle/low income countries/territories suffering a disproportionately high loss of LE due to RID. Additionally, loss of LE due to RID decreased remarkably by 0.97 years globally during the period 1990-2017 but increased slightly among populations older than 70 years and in many high income countries/territories. Results suggest that RID still pose a severe threat for population and public health, and that amid dramatic sociodemographic changes globally, the disease burden of RID may resurge. The study presents the first examination of the life-shortening effect of RID at the global and country/territory levels, providing new understanding of the changing disease burden of RID and shedding light on the potential consequences of the current COVID-19 pandemic.
\end{abstract}

Keywords Loss of life expectancy $\cdot$ Cause-eliminated life expectancy $\cdot$ Respiratory infectious diseases · Disease burden · Population ageing · Global Burden of Disease Study

Fei Guo

fei.guo@mq.edu.au

Extended author information available on the last page of the article 


\section{Introduction}

The world's populations have experienced profound changes in mortality and disease patterns over the past several decades, seeing mortality from infectious diseases $^{1}$ decreasing substantially (Ahsan Karar et al., 2009; Albala \& Vio, 1995; Mackenbach, 1993; Smallman-Raynor \& Phillips, 1999; Stevens et al., 2008). For example, mortality from infectious diseases in the United States (US) stood at 797 per 100,000 persons in 1900, resulting in more than one-third of all deaths, while in 1996 , this mortality rate decreased remarkably to 59 per 100,000 persons, accounting for less than 7\% of all deaths (Armstrong et al., 1999; Centers for Disease Control Prevention, 1999a). The impressive declining mortality rate from infectious diseases is driven by a series of progresses in public health and socioeconomic development achieved in the twentieth century, such as advances in nutrition, antibiotics, vaccination, hygiene, and sanitisation (Cohen, 2000; Hinman, 1998). The declining trend in mortality from infectious diseases is anticipated to continue throughout the new millennium, with expectations of further controlled mortality from infectious diseases and successful eradication of some specific infectious diseases (Kumate, 1997).

While the overall declining trend in mortality from infectious diseases is encouraging, a number of sociodemographic changes have caused growing concerns over the emergence of new infectious diseases or the re-emergence of controlled infectious diseases (Fauci, 2001). For example, the proportion of the global population residing in middle/low income countries/territories ${ }^{2}$ has been progressively increasing, leading to concerns about the increased susceptibility of populations to infectious diseases given that the prevalence of infectious diseases remains relatively high in middle/low income countries/territories (Cohen, 2000; Gavazzi et al., 2004). The unprecedented trend of population ageing creates further concerns about the increased vulnerability of populations to infectious diseases given that the growing number of elderly people suffer decreased efficiency of immune response and an increased risk of having chronic diseases that may induce infectious diseases (Cohen, 2000; Gavazzi et al., 2004). Other social and demographic changes, such as intensifying international migration and travel and familial changes in childbearing, also profoundly affect the mortality pattern of infectious diseases and the approaches to infectious disease prevention and control (Louhiala et al., 1995; Pavia, 2007).

\footnotetext{
${ }^{1}$ Cause-specific mortality from certain diseases is expressed as mortality from certain diseases in this study for succinctness.

2 The classification of high income countries/territories, middle income countries/territories (upper-middle income countries/territories and lower-middle income countries/territories) and low income countries/territories is based on the standard of the World Bank in 2017: high income countries/territories (gross national income [GNI] per capita $\geq \mathrm{US} \$ 12,476$ ); upper-middle income countries/territories (GNI per capita US\$4,036-US\$12,475); lower-middle income countries/territories (GNI per capita US\$1,026US\$4,035); and low income countries/territories (GNI per capita $\leq$ US $\$ 1,025$ ). For full lists of countries/ territories under each category please refer to https://datahelpdesk.worldbank.org/knowledgebase/artic les/906519-world-bank-country-and-lending-groups or Appendix A.
} 
Respiratory infectious diseases (RID) are among the infectious diseases attracting the greatest attention primarily because of their serious threat to population and public health. RID are the most deadly and the most widely spread types of infectious diseases, resulting in more than 3.8 million deaths globally in 2017, and accounting for $46 \%$ of the deaths caused by infectious diseases that year (Global Burden of Disease Study, 2017). The mortality from RID increases dramatically with age, creating an exceptionally severe threat for the growing elderly populations (Byng-Maddick \& Noursadeghi, 2016; Gardner, 1980; Haq \& McElhaney, 2014; Yamaya et al., 2002). Emergencies of RID are also catastrophically destructive, with RID being responsible for a large proportion of past pandemics (e.g., the 1918 influenza pandemic, the 1968 influenza pandemic, and the 2009 H1N1 pandemic) and for three World Health Organization Public Health Emergency of International Concerns in the new millennium. For example, the currently ongoing COVID-19 pandemic, caused by severe acute respiratory syndrome coronavirus 2 (SARS-CoV-2), is the latest destructive global disruption caused by RID, tragically resulting in substantial mortality and morbidity worldwide.

Given the rapid sociodemographic changes and the significant threat of RID to population and public health, it is timely to revisit the mortality patterns and disease burden of RID and investigate whether and how they have changed. To this end, this study presents a comprehensive examination on the loss of life expectancy (LE) due to RID in 195 countries/territories over a period of almost three decades to explore the patterns of and changes in mortality from RID. This analysis provides the first attempt to quantify and monitor the life-shortening effect of RID at the global and country/territory levels, providing a more nuanced understanding of the changing health effects of RID amid rapidly changing sociodemographic dynamics. The results have important implications for health policies in RID control and prevention, and shed light on strategies to cope with the profound challenges brought by the current COVID-19 pandemic and future outbreaks of RID.

\section{Changing disease burden of respiratory infectious diseases}

\section{Epidemiological transition and declining mortality from respiratory infectious diseases}

When a society is experiencing socioeconomic development and advances in medical technology and disease prevention, there are corresponding changes to patterns of mortality, LE, and causes of death (McKeown, 2009; Santosa et al., 2014). According to the theory of epidemiological transition, infectious diseases are common at the early stage of the epidemiological transition, accounting for most deaths and precluding an increase in LE and population growth. However, in the later stages of epidemiological transition, which see a declining prevalence of the epidemic and increasing food sufficiency, the mortality from infectious diseases decreases markedly, leading to increased LE, population growth, and the transition of disease pattern from an infectious diseases dominant pattern to a chronic diseases dominant pattern (Omran, 1971, 1983, 1998). 
Historical changes in mortality from RID have largely reflected the changes described by epidemiological transition theory, with a drastic decrease in mortality from RID observed in many countries/territories worldwide (Smallman-Raynor \& Phillips, 1999; Stevens et al., 2008). For example, the mortality from RID decreased by $79 \%$ in Bangladesh during the period 1986-2006 (Ahsan Karar et al., 2009); by $70 \%$ in the US during the period 1950-2017 (Centers for Disease Control \& Prevention, 2018); and by $43 \%$ in Chile during the period 1972-1992 (Albala \& Vio, 1995). This tremendous decline of mortality from RID is also observed at the global level, with the disease burden of major RID, such as lower respiratory infection and tuberculosis, decreasing by approximately 50\% since 1990 (Murray et al., 2015). The declining mortality from RID is more significant among children and in high income countries/territories (Corrêa et al., 2017; Troeger et al., 2018). For example, the number of deaths caused by lower respiratory infection decreased worldwide by $54 \%$ among children younger than 5 years of age during the period 2000-2016, and by approximately $13 \%$ among all ages over the same period. Additionally, the mortality from lower respiratory infection decreased to less than 4 per 100,000 persons in Western Europe, North America (excluding Central America and the Caribbean), and Australasia $^{3}$ in 2016, but remained at more than 125 per 100,000 persons in Sub-Saharan Africa and South Asia in the same year (Troeger et al., 2018).

\section{Effect of sociodemographic changes on disease burden of respiratory infectious diseases}

Despite an overall declining mortality from RID, researchers argue that it is too soon to be complacent about the achieved success given that the rapid sociodemographic changes seen around the world may lead to the emergence or re-emergence of RID (Castelli \& Sulis, 2017; Cohen, 2000; Fauci, 2001; Gavazzi \& Krause, 2002; Gavazzi et al., 2004; Michaud, 2009). First, infectious diseases, referred to as 'diseases of poverty', remain one of the major types of diseases causing mortality and morbidity in middle/low income countries, primarily because of malnutrition, poor sanitation, and limited access to treatment (Stevens, 2004). It is estimated that the developing world suffers nearly $97 \%$ of the global deaths caused by infectious diseases, with RID accounting for a larger proportion of these deaths than any other type of infectious diseases (Michaud, 2009). With an increasing proportion of the global population residing in middle/low income countries/territories, the vulnerability of populations to RID and other types of infectious diseases are expected to increase correspondingly (Cohen, 2000; Gavazzi et al., 2004). For example, the population of Sub-Saharan Africa represented 7\% of the global population in 1950, $14 \%$ in 2018 , and is estimated to increase to $35 \%$ by the end of this century (United Nations, 2019a, 2019b), suggesting a possible surge in the susceptibility of populations to infections (e.g. tuberculosis and human immunodeficiency viruses), that severely affect Sub-Saharan Africa (Lalloo \& Pillay, 2008).

\footnotetext{
3 Australasia refers to Australia and New Zealand.
} 
More importantly, the unprecedented trend of population ageing, an established trend globally but more significant in the developed world (Appendix B), will also contribute to a greater susceptibility of populations to RID (Cohen, 2000). RID cause particularly high mortality and morbidity among elderly people (Byng-Maddick \& Noursadeghi, 2016; Leibovici, 1995; Yoshikawa \& Marrie, 2000). For example, the incidence of community-acquired pneumonia is 91.6 per 100,000 persons for people aged 45 and younger, but increases to 1012.3 per 100,000 persons for people aged 65 and older (Marston et al., 1997). Meanwhile, the mortality from pneumonia increases by more than 250 times when age increases from 15 to 34 to 75 and older, and for the same age increase, by 13 times for tetanus and by 17 times for renal infections (Gardner, 1980). Similarly, the case fatality rate of COVID-19 increases dramatically with age and peaks among people aged 80 and older (Appendix C). The higher frequency and more severe consequences of RID for elderly people are primarily caused by age-related factors, such as immunosenescence, increased risks of RID induced by chronic diseases, and the difficulty of diagnosing and treating RID for the elderly (Byng-Maddick \& Noursadeghi, 2016; Gavazzi \& Krause, 2002; High, 2002). Consequently, the ongoing trend of population ageing will profoundly affect the existing patterns of mortality and morbidity of RID and create new challenges in disease prevention and control for population and public health (ByngMaddick \& Noursadeghi, 2016).

In addition to the global population's changes in geographic distribution and age structure, other sociodemographic changes are also contributing to growing concerns about the susceptibility of populations to RID. For example, increasing international migration and travel can accelerate the spread of infectious diseases, particularly airborne diseases such as RID (Castelli \& Sulis, 2017; MacPherson et al., 2007). The efficiency and prolificness of modern transportation systems means that RID may spread to any part of the world within 24 hours (Pavia, 2007). A number of outbreaks of RID, such as the spread of influenza associated with Alaskan cruises in 1998 (Centers for Disease Control Prevention, 1999b), the outbreak of SARS in 2003 (Booth et al., 2003), and the current COVID-19 pandemic (Sohrabi et al., 2020), have demonstrated the important role of international travel in spreading RID. A further example is that familial changes in childbearing also contribute to the transmission of RID (Cohen, 2000). The dwindling size of families and increased female participation in labour market increase the use of day care services for children, which is associated with an elevated risk of exposure to infectious diseases (primarily RID and enteric diseases) arising from children's close contact and the underdeveloped immune function of children (Alexandrino et al., 2016; Hutto et al., 1985; Louhiala et al., 1995; Pickering et al., 1986).

\section{Existing research on changes in disease burden of respiratory infectious diseases and major limitations of such research}

The profound sociodemographic changes discussed above have important effects on the patterns of mortality from RID and may fundamentally reshape the disease burden of RID. This necessitates a more nuanced understanding of how the disease burden 
of RID changes when societies and demographics change rapidly. Several studies have investigated the patterns of and changes in mortality from RID and report some worrying trends in the disease burden of RID. For example, Troeger et al. (2018) note that while the mortality of the elderly population remains largely unchanged in Brazil and India, the number of deaths caused by lower respiratory infection among people aged 70 and older has increased dramatically since 1990 in these two nations, even exceeding the growing speed of the size of the population of this age group over the same period, reflecting an increase in both mortality and the number of deaths caused by RID for the elderly. Similarly, several studies indicate that the mortality from specific RID, such as tuberculosis, has been rising in some countries, such as Thailand and Bangladesh, against the overall declining trend in disease burden of infectious diseases in these countries (Ahsan Karar et al., 2009; Aungkulanon et al., 2013). More importantly, Armstrong et al. (1999) report that the long-term declining trend in mortality from infectious diseases, which is a remarkable success in infectious disease prevention and control, has been reversed in the US, partly because of the increasing disease burden of RID, primarily driven by the growing mortality from pneumonia and influenza among people aged 65 and older since the 1980s.

However, existing understanding of the patterns of and changes in disease burden of RID is currently inadequate. Previous research tends to focus on one specific disease of RID (Troeger et al., 2018, 2019), certain age groups (Nair et al., 2010, 2011; Shi et al., 2020; Troeger et al., 2020), or the experience in a specific region or country (Corrêa et al., 2017; GBD 2015 Eastern Mediterranean Region Lower Respiratory Infections Collaborators, 2018). Little is known about the patterns and changing trends in disease burden of RID from a global perspective and the corresponding differences by country and territory, thus there is little comprehensive understanding of overall trends and the geographic heterogeneity of the changing disease burden of RID.

To fill these research gaps, the present study provides a comprehensive examination of the loss of LE due to RID in 195 countries/territories over a period of almost three decades. Loss of LE due to RID is an important indicator measuring the health impacts of RID and an easy and powerful way to quantify the life-shortening effect of RID at a population level (Chiang, 1979; Keyfitz, 1977; Tsai et al., 1978). The study provides the first examination of the loss of LE due to RID at both the global and country/territory levels, providing a timely and more nuanced understanding of the changing disease burden of RID and the consequences of RID on population and public health. The results of this study will inform policies and practices in the global response to the current COVID-19 pandemic and the prevention and control of future emergencies of RID.

\section{Data and Methods}

\section{Data}

This study uses the database of the Global Burden of Disease Study (GBD), which is the most comprehensive observational epidemiological study in the world, providing 
data on mortality and morbidity from major diseases, injuries, and risk factors at global, regional, and national levels from 1990 to the present (Kyu et al., 2018). The methods of the GBD in collecting and processing data have been presented in detail elsewhere (Abubakar et al., 2015; Lozano et al., 2012; Wang et al., 2012), and are summarised briefly below.

The GBD aims to collect all available data on mortality and morbidity from multiple sources, including vital registrations, censuses, surveys, and published studies. A coherent measurement framework and standardised estimation methods are adopted by the GBD to achieve comparability of data across countries/territories and years (Chen et al., 2019). Three general principles are adhered to for data processing in the GBD: data completeness evaluation; consistent statistical estimation, and estimated data quality reassessment. First, data from each source are assessed regarding data completeness by evaluating the coverage of the registration system, the cause composition of death, and the consistency with other data sources in the same or similar country at the same time (Lozano et al., 2012). Second, assessed data are redistributed and mapped according to the International Statistical Classification of Diseases Data and are used to estimate all-cause and cause-specific mortality and morbidity and corresponding age and gender distribution based on certain models. Specifically, all-cause mortality is estimated using the CoDCorrect algorithm while cause-specific mortality is estimated using a number of modelling approaches, such as Cause of Death Ensemble Modelling, negative binomial models, and fixed proportion models, depending on the quality of available data and the performance of used models (Wang et al., 2012). Age-and-gender data are estimated by aggregating and splitting data into standardised sets of age groups using the age splitting model and the age-gender splitting model developed by the GBD research team (Abubakar et al., 2015). Third, all estimated data are re-evaluated and corrected through several steps, including cross-validation analysis, outlier detection, and data smoothing techniques, to enhance the quality of data (Lozano et al., 2012).

\section{Measurement of respiratory infectious diseases}

The GBD measures RID based on the tenth revision of the International Statistical Classification of Diseases (World Health Organization, 2004). This classification identifies that there are four major types RID: upper respiratory infections, lower respiratory infections, tuberculosis, and otitis media. Upper respiratory infections are defined as the illnesses caused by an acute infection involving the upper respiratory tract; these infections are triggered by viruses and bacteria and present symptoms such as nasal obstruction, sore throat, and tonsillitis. Low respiratory infections are defined as pneumonia and acute bronchitis, which are caused by infections involving the lower respiratory tract and present symptoms such as fever, coughing, and shortness of breath (Troeger et al., 2017). Tuberculosis has three major types: latent tuberculosis infection, drug-susceptible tuberculosis, and multidrug-resistant tuberculosis without extensive drug resistance, which most often affect the lung with typical symptoms varying by type of tuberculosis. Otitis media is defined as a group 
of inflammatory diseases of the middle ear that are caused by bacteria or viruses and result in ear pain, trouble hearing, and fever (Mathers et al., 2003).

\section{Methods}

This study uses the research approaches of life table and cause-eliminated life table to estimate the loss of LE due to RID. The methods are presented in detail in Appendix $\mathrm{D}$ and are described briefly below.

First, based on the all-cause mortality data from 1990 and 2017 sourced from the GBD, this study constructs abridged life tables for 195 countries/territories to compute LE, denoted by $e$ (Eqs. 1-10). The life tables include the following 18 age groups: less than 1 year; $1-4$ years; 5-year age groups from 5-9 years to 75-79 years; 80 years and older. The study constructs life tables for men, women, and both genders following the method proposed by Chiang (1979).

Next, based on the data on all-cause mortality and cause-specific mortality from RID presented in the GBD, the study develops RID-eliminated life tables for 195 countries/territories to compute LE when RID are eliminated, represented by $e^{-R I D}$ (Eqs. 11-17). This step adopts the method proposed by Smith (1985).

Finally, after LE $(e)$ and RID-eliminated LE $\left(e^{-R I D}\right)$ are computed, the study estimates absolute length of loss of LE due to RID, represented by $e^{L}$, by subtracting $e$ from $e^{-R I D}$ (Eq. 18), and its ratio to LE $(e)$ as well as the changes in these two indicators between 1990 and 2017.

\section{Results}

\section{Global distribution of mortality from respiratory infectious diseases}

This study firstly explores the demographic and geographic location distribution of mortality from RID, which reveals that RID still impose significant threat to population and public health. Although mortality from RID decreased from 96 per 100,000 persons in 1990 to 49.1 per 100,000 persons in 2017 worldwide (Table 1), it still ranked fourth among the 21 major types of diseases and injuries and first among all types of infectious diseases in 2017 (Fig. 1), indicating that despite a rapid decrease in disease burden of RID over the past several decades, RID remain the most dangerous infectious diseases worldwide. Additionally, mortality from RID exhibits remarkable differences by gender, age, and geographic location. First, globally, men have a higher mortality from RID than do women, with male mortality from RID for all ages standing higher than that of women by 11 per 100,000 persons in 2017 (Table 2). The higher male mortality from RID was particularly prominent at ages older than 35, with male mortality from RID almost twice that of female, suggesting that men are more vulnerable to RID than are women.

Second, mortality from RID was found to have a rough J-shaped distribution by age. Overall, mortality from RID reached more than 400 per 100,000 persons among the age group of less than 1 year, but decreased and remained stable after this 
Table 1 Trends of mortality rate of RID (per 100,000 persons) and its ranking among major diseases and injuries, 1990-2017

\begin{tabular}{|c|c|c|c|c|c|c|c|}
\hline & $\begin{array}{l}\text { Ranking among } 21 \\
\text { major diseases and } \\
\text { injuries }\end{array}$ & $\begin{array}{l}\text { Ranking among all } \\
\text { types of infectious } \\
\text { diseases }\end{array}$ & Global & HIC & UMIC & LMIC & LIC \\
\hline 1990 & 3 & 1 & 96.0 & 34.2 & 55.7 & 143.8 & 260.9 \\
\hline 1991 & 3 & 1 & 94.0 & 34.3 & 53.4 & 140.9 & 254.9 \\
\hline 1992 & 3 & 1 & 92.6 & 34.5 & 51.6 & 138.7 & 250.0 \\
\hline 1993 & 3 & 1 & 90.1 & 35.4 & 49.5 & 133.5 & 245.2 \\
\hline 1994 & 3 & 1 & 87.7 & 35.6 & 47.6 & 128.9 & 240.0 \\
\hline 1995 & 3 & 1 & 85.5 & 36.2 & 45.3 & 125.2 & 234.4 \\
\hline 1996 & 3 & 1 & 83.0 & 36.2 & 42.7 & 121.5 & 227.6 \\
\hline 1997 & 3 & 1 & 81.2 & 36.2 & 40.3 & 119.5 & 220.4 \\
\hline 1998 & 3 & 1 & 79.3 & 36.3 & 38.3 & 116.7 & 213.9 \\
\hline 1999 & 3 & 1 & 77.3 & 36.3 & 36.8 & 113.4 & 207.6 \\
\hline 2000 & 3 & 1 & 75.3 & 35.2 & 35.6 & 110.2 & 201.3 \\
\hline 2001 & 3 & 1 & 72.8 & 33.9 & 34.0 & 106.3 & 193.5 \\
\hline 2002 & 3 & 1 & 70.6 & 33.7 & 32.9 & 102.6 & 185.7 \\
\hline 2003 & 3 & 1 & 68.5 & 33.6 & 31.9 & 98.6 & 178.5 \\
\hline 2004 & 3 & 1 & 66.0 & 32.9 & 30.9 & 94.1 & 171.0 \\
\hline 2005 & 3 & 1 & 64.5 & 33.1 & 30.1 & 91.3 & 164.4 \\
\hline 2006 & 3 & 1 & 62.7 & 32.7 & 28.7 & 88.6 & 158.8 \\
\hline 2007 & 3 & 1 & 61.0 & 32.7 & 27.5 & 85.9 & 153.2 \\
\hline 2008 & 3 & 1 & 59.7 & 32.8 & 27.1 & 83.5 & 147.3 \\
\hline 2009 & 3 & 1 & 57.9 & 32.6 & 26.8 & 79.8 & 141.5 \\
\hline 2010 & 3 & 1 & 56.2 & 32.8 & 26.5 & 76.4 & 135.7 \\
\hline 2011 & 3 & 1 & 54.8 & 33.4 & 26.0 & 73.7 & 130.5 \\
\hline 2012 & 3 & 1 & 53.9 & 34.0 & 25.6 & 72.1 & 125.9 \\
\hline 2013 & 3 & 1 & 53.3 & 34.4 & 25.3 & 71.0 & 121.9 \\
\hline 2014 & 3 & 1 & 52.4 & 34.6 & 25.2 & 69.2 & 118.4 \\
\hline 2015 & 3 & 1 & 51.5 & 35.5 & 25.2 & 67.0 & 114.5 \\
\hline 2016 & 3 & 1 & 50.4 & 35.8 & 25.4 & 64.6 & 110.3 \\
\hline 2017 & 4 & 1 & 49.1 & 36.1 & 25.0 & 62.6 & 105.4 \\
\hline
\end{tabular}

Data source: Global Burden of Disease Study (2017)

HIC high income countries/territories, UMIC upper-middle income countries/territories, LMIC lowermiddle income countries/territories, LIC low income countries/territories

age group until the age of 60 , after which, the rate increased dramatically to more than 600 per 100,000 persons in the age group of 80 years and older (Table 2). This indicates that compared with people of working age, young children and older adults are more vulnerable to RID, implying that the disease burden of RID is disproportionately borne by very young children and even more by elderly people.

Third, mortality from RID demonstrates considerable geographic disparity. Globally, low income countries/territories suffered the highest mortality from RID (105.4 


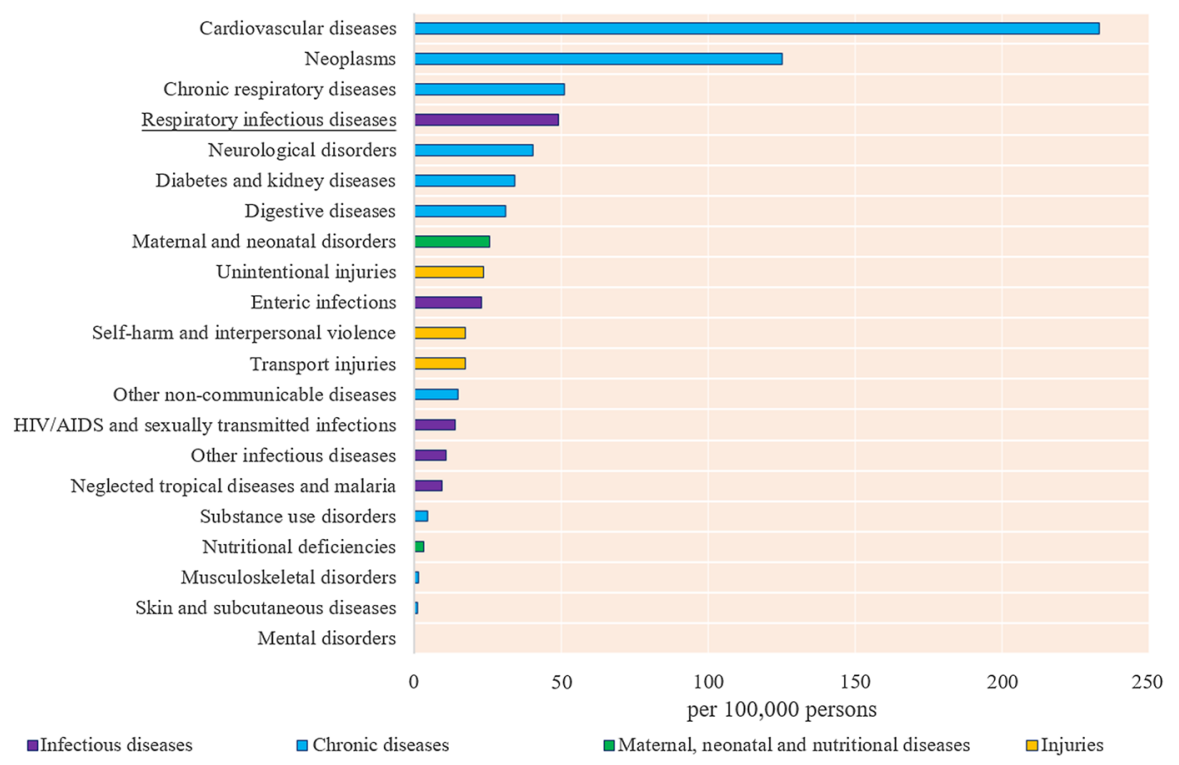

Fig. 1 Global cause-specific mortality of 21 major types of diseases in 2017. Data source: Global Burden of Disease Study (2017)

per 100,000 persons) in 2017 (Table 2). As shown in Fig. 2, the highest rates were in the Central African Republic (255.3 per 100,000 persons); Lesotho (180.5 per 100,000 persons); and South Sudan (177.6 per 100,000 persons). Lower-middle income countries/territories (largely located in South Asia and Southeast Asia) had the next highest rates (62.6 per 100,000 persons). By contrast, high income countries/territories (such as those in Southern Europe, Western Europe, and North America) had significantly lower rates (less than 40 per 100,000 persons) in the same year. These results suggest that disease burdens of RID are borne unevenly globally, with middle/low income countries/territories, particularly those in SubSaharan Africa, South Asia, and Southeast Asia, suffering a higher mortality from RID than that found in the rest of the world.

Importantly, mortality from RID in different geographic locations also exhibited various changing trends over the period 1990-2017. According to Table 1, while mortality from RID decreased significantly in low income countries/territories (from 260.9 per 100,000 persons to 105.4 per 100,000 persons), lower-middle income countries/territories (from 143.8 per 100,000 persons to 62.6 per 100,000 persons), and upper-middle income countries/territories (from 55.7 per 100,000 persons to 25 per 100,000 persons) between 1990 and 2017, it increased slightly in high income countries/territories (from 34.2 per 100,000 persons to 36.1 per 100,000 persons) over the same period. The increasing trend of mortality from RID in high income countries/territories was particularly prominent in relation to lower respiratory infections (from 30.6 per 100,000 persons to 34.8 per 100,000 persons) while the rates for other three causes categorised under RID declined to a notably smaller extent in high income countries/territories than that in middle/low income countries/ 
Table 2 Global mortality rate of RID by age, gender, and country income in 2017, per 100,000 persons

\begin{tabular}{lrrrrrrr}
\hline & Global & Male & Female & HIC & UMIC & LMIC & LIC \\
\hline$<$ 1 year & 463.7 & 464.8 & 462.4 & 9.5 & 113.0 & 593.8 & 764.8 \\
1-4 years & 42.6 & 40.9 & 44.3 & 1.0 & 6.7 & 50.4 & 103.7 \\
5-9 years & 5.5 & 5.1 & 6.0 & 0.3 & 1.2 & 4.4 & 8.3 \\
10-14 years & 3.4 & 3.3 & 3.5 & 0.4 & 1.8 & 6.0 & 14.1 \\
15-19 years & 4.8 & 4.8 & 4.8 & 0.7 & 2.7 & 10.3 & 25.1 \\
20-24 years & 7.8 & 8.9 & 6.7 & 1.1 & 3.4 & 14.9 & 37.5 \\
25-29 years & 9.9 & 11.8 & 8.0 & 1.6 & 4.7 & 20.6 & 50.5 \\
30-34 years & 13.2 & 16.7 & 9.6 & 2.1 & 6.4 & 28.0 & 66.5 \\
35-39 years & 17.6 & 22.6 & 12.5 & 3.0 & 7.8 & 37.1 & 86.1 \\
40-44 years & 21.8 & 28.7 & 14.8 & 4.3 & 9.6 & 49.0 & 116.2 \\
45-49 years & 27.3 & 37.5 & 17.0 & 0.3 & 1.9 & 7.0 & 12.6 \\
50-54 years & 38.8 & 49.8 & 28.0 & 6.6 & 13.2 & 72.8 & 172.5 \\
55-59 years & 55.5 & 74.1 & 37.5 & 10.5 & 21.6 & 101.5 & 243.1 \\
60-64 years & 74.0 & 95.8 & 53.2 & 17.1 & 29.5 & 143.2 & 324.2 \\
65-69 years & 105.1 & 134.4 & 78.2 & 27.4 & 45.6 & 211.3 & 441.8 \\
70-74 years & 170.0 & 208.5 & 135.7 & 52.3 & 83.0 & 344.8 & 696.5 \\
75-79 years & 240.7 & 302.8 & 190.6 & 108.6 & 150.3 & 481.5 & 1016.3 \\
$\geq 80$ years & 609.8 & 741.6 & 525.1 & 533.4 & 493.7 & 982.7 & 2012.0 \\
Total & 49.1 & 54.6 & 43.6 & 36.1 & 25.0 & 62.6 & 105.4 \\
\hline
\end{tabular}

Data source: Global Burden of Disease Study (2017)

HIC high income countries/territories, UMIC upper-middle income countries/territories, LMIC lowermiddle income countries/territories, LIC low income countries/territories

territories (Fig. 3). Consequently, the importance of causes grouped under the RID category changed differently across countries and territories. Since the 1990s, the share of lower respiratory infections increased in high income and upper-middle income countries/territories while it decreased in lower-middle income and low income countries/territories (Table 3). By contrast, the proportion of tuberculosis decreased in high income countries/territories and upper-middle countries/territories but grew in lower-middle income countries/territories and low income countries/territories (Table 3).

\section{Loss of life expectancy due to respiratory infectious diseases in 1990 and 2017}

Analysis on the RID-eliminated life tables for 195 countries/territories in 1990 and 2017 shows that loss of LE caused by RID differs widely by age, gender, and geographic location, as presented in Table 4 and Figs. 4,5 and $6 .^{4}$

\footnotetext{
${ }^{4}$ Detailed estimates of loss of LE due to RID are presented in Appendices E and F given the limit of space.
} 


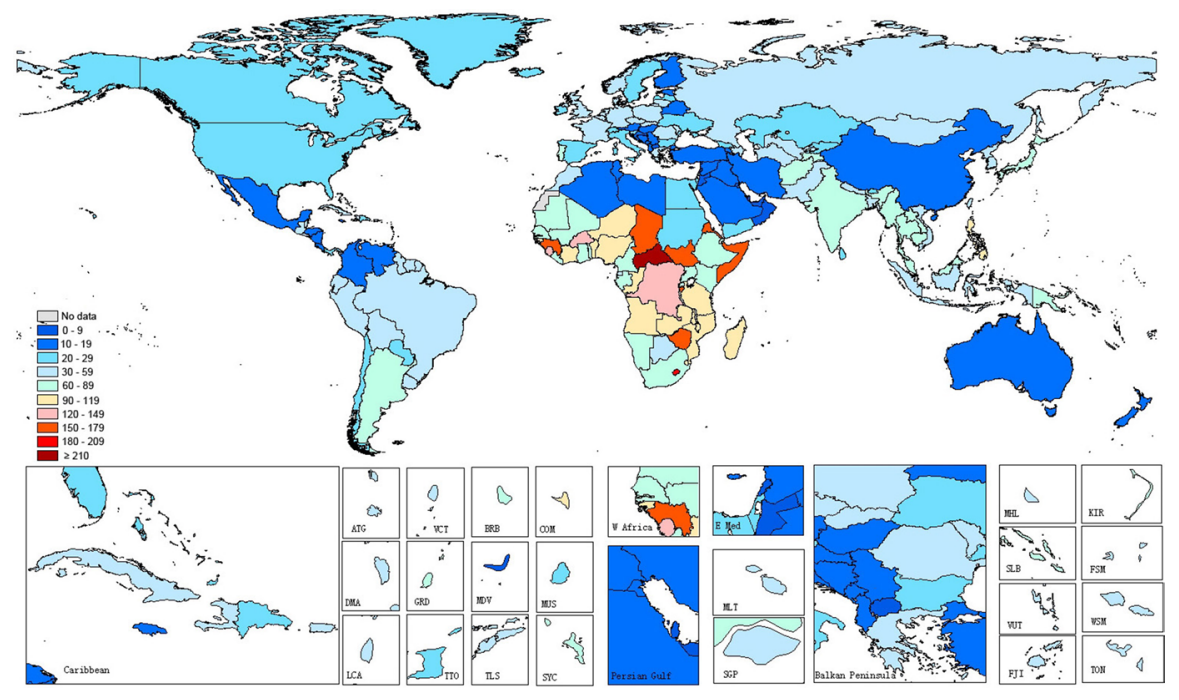

Fig. 2 Mortality from RID by country and territory in 2017 (per 100,000 persons). ATG Antigua and Barbuda, VCT Saint Vincent and the Grenadines, BRB Barbados, COM Comoros, DMA Dominica, GRD Grenada, MDV Maldives, MUS Mauritius, LCA Saint Lucia, TTO Trinidad and Tobago, TLS TimorLeste, SYC Seychelles, MLT Malta, SGP Singapore, MHL Marshall Islands, KIR Kiribati, SLB Solomon Islands, FSM Federated States of Micronesia, VUT Vanuatu, WSM Samoa, FJI Fiji, TON Tonga. Data source: Global Burden of Disease Study (2017)

As presented in Table 4, global LE increases vary in different age groups, ranging from 0.5 to 2.3 years in 1990 and from 0.5 to 1.3 years for 2017 if RID are eliminated. In relative terms, the proportion of loss of LE due to RID in remaining LE increases by $1.21-6.20 \%$ at different ages, peaking among those aged 80 and older. For example, in 2017, the proportion of loss of LE due to RID in remaining LE for age group 80 and older reached $6.34 \%$ for men (compared with $1.84 \%$ at birth and $2.11 \%$ for the age group $40-45$ ) and $5.20 \%$ for women (compared with $1.65 \%$ at birth and $1.68 \%$ for the age group 40-45). This suggests that the life-shortening effect of RID is relatively stronger among the elderly than among people in younger age groups.

Additionally, loss of LE due to RID is slightly greater for men, with male loss of LE due to RID remaining higher than it is for women by $0.01-0.18$ years in all age groups. The greater male loss of LE due to RID is particularly significant in the age group 35-40 in which it is greater than it is for women by 0.18 years in 1990 and 0.1 years in 2017. In addition, the male proportion of loss of LE due to RID in remaining LE is also greater than that of women in all age groups, with the gender gap in proportion of loss of LE due to RID in remaining LE increasing with age, peaking in the age group 80 and older (by $1.78 \%$ in 1990 and $1.13 \%$ in 2017). This suggests that men are more vulnerable to RID and suffer more severe health outcomes from RID.

Loss of LE due to RID also differs considerably by geographic location (Figs. 4 and 5), and reveals a negative association with gross domestic product 

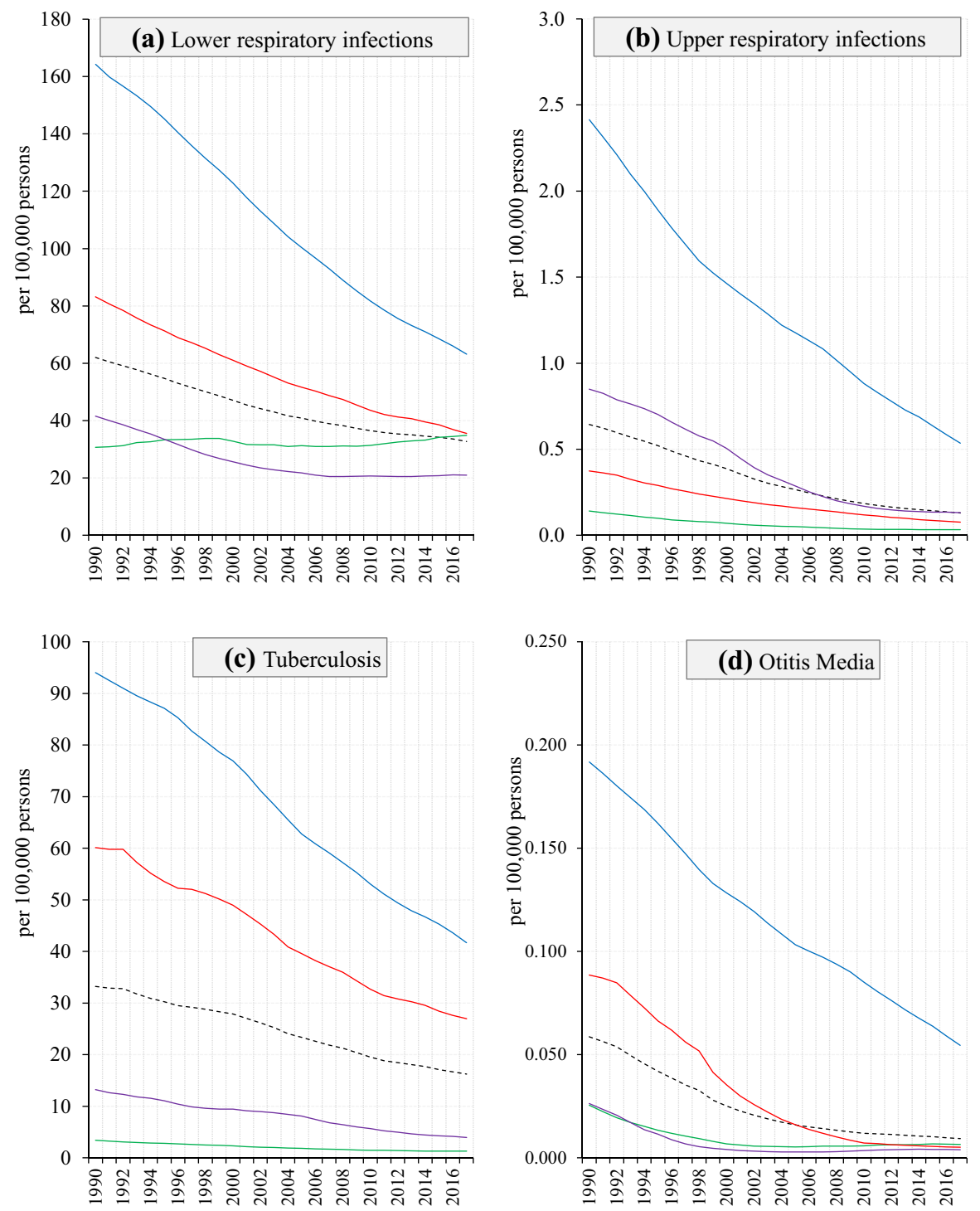

Globally - HIC — UMIC - LMIC - LIC

Fig. 3 Trends in cause-specific mortality of four types of RID, 1990-2017. HIC high income countries/ territories, UMIC upper-middle income countries/territories, LMIC lower-middle income countries/territories, LIC low income countries/territories. Data source: Global Burden of Disease Study (2017)

(GDP) per capita (Fig. 6), suggesting that middle/low income countries/territories are more susceptible to RID given their socioeconomic disadvantages. Results show that, while most high income countries/territories (largely located in Europe, North America [excluding Central America and the Caribbean], and Australasia) 
Table 3 Share of the four causes categorised under RID in mortality rate from RID (\%), globally and by country income
Upper respira- Lower respira- Tuberculosis Otitis media tory infections tory infections

\section{Global}

$1990 \quad 0.68$

64.65

34.61

0.06

19950.61

64.00

35.34

0.05

$2000 \quad 0.52$

62.47

36.98

0.03

$2005 \quad 0.41$

63.34

36.23

0.02

$2010 \quad 0.33$

64.87

34.78

0.02

$2015 \quad 0.28$

66.45

33.25

0.02

$2017 \quad 0.26$

66.71

33.01

0.02

High income countries/territories

$\begin{array}{rlrrr}1990 & 0.41 & 89.51 & 10.01 & 0.07 \\ 1995 & 0.27 & 91.95 & 7.74 & 0.04 \\ 2000 & 0.20 & 93.23 & 6.55 & 0.02 \\ 2005 & 0.15 & 94.33 & 5.50 & 0.02 \\ 2010 & 0.11 & 95.34 & 4.53 & 0.02 \\ 2015 & 0.09 & 96.24 & 3.65 & 0.02 \\ 2017 & 0.09 & 96.32 & 3.57 & 0.02\end{array}$

Upper-middle income countries/territories

$\begin{array}{lllll}1990 & 1.53 & 74.67 & 23.75 & 0.05 \\ 1995 & 1.55 & 73.99 & 24.43 & 0.03 \\ 2000 & 1.42 & 72.08 & 26.49 & 0.01 \\ 2005 & 0.95 & 72.18 & 26.86 & 0.01 \\ 2010 & 0.63 & 78.02 & 21.34 & 0.01 \\ 2015 & 0.54 & 82.55 & 16.89 & 0.02 \\ 2017 & 0.53 & 83.77 & 15.68 & 0.02\end{array}$

Lower-middle income countries/territories

$\begin{array}{lllll}1990 & 0.26 & 57.86 & 41.82 & 0.06 \\ 1995 & 0.23 & 56.95 & 42.77 & 0.05 \\ 2000 & 0.19 & 55.36 & 44.42 & 0.03 \\ 2005 & 0.18 & 56.48 & 43.32 & 0.02 \\ 2010 & 0.16 & 57.05 & 42.78 & 0.01 \\ 2015 & 0.13 & 57.47 & 42.39 & 0.01 \\ 2017 & 0.12 & 56.83 & 43.04 & 0.01\end{array}$

Low income countries/territories

$\begin{array}{lllll}1990 & 0.93 & 62.96 & 36.04 & 0.07 \\ 1995 & 0.81 & 61.96 & 37.16 & 0.07 \\ 2000 & 0.73 & 61.00 & 38.21 & 0.06 \\ 2005 & 0.72 & 61.04 & 38.18 & 0.06 \\ 2010 & 0.65 & 60.21 & 39.08 & 0.06 \\ 2015 & 0.56 & 59.83 & 39.55 & 0.06 \\ 2017 & 0.51 & 59.89 & 39.55 & 0.05\end{array}$

Data source: Global Burden of Disease Study (2017) 
Table 4 Global LE $(e)$, RID-eliminated LE $\left(e^{-R I D}\right)$ and loss of LE due to RID $\left(e^{L}\right)$ at selected ages and by gender, in 1990 and 2017 (Years)

\begin{tabular}{|c|c|c|c|c|c|c|c|c|c|}
\hline & \multicolumn{4}{|l|}{1990} & \multicolumn{4}{|l|}{2017} & \multirow[b]{2}{*}{$e_{2017}^{L}-e_{1990}^{L}$} \\
\hline & $e_{1990}$ & $e_{1990}^{-R I D}$ & $e_{1990}^{L}$ & $e_{1990}^{L} / e_{1990}(\%)$ & $e_{2017}$ & $e_{2017}^{-R I D}$ & $e_{2017}^{L}$ & $e_{2017}^{L} / e_{2017}(\%)$ & \\
\hline \multicolumn{10}{|c|}{ Both genders } \\
\hline 0 & 65.67 & 67.93 & 2.26 & 3.44 & 73.27 & 74.56 & 1.29 & 1.76 & -0.97 \\
\hline 1 & 68.80 & 70.27 & 1.47 & 2.14 & 74.41 & 75.38 & 0.97 & 1.30 & -0.50 \\
\hline 5 & 66.72 & 67.83 & 1.11 & 1.66 & 71.16 & 72.02 & 0.86 & 1.21 & -0.25 \\
\hline 10 & 62.19 & 63.26 & 1.07 & 1.72 & 66.37 & 67.22 & 0.84 & 1.27 & -0.23 \\
\hline 15 & 57.45 & 58.50 & 1.05 & 1.83 & 61.53 & 62.37 & 0.83 & 1.35 & -0.22 \\
\hline 20 & 52.80 & 53.83 & 1.03 & 1.95 & 56.78 & 57.60 & 0.82 & 1.44 & -0.21 \\
\hline 25 & 48.25 & 49.25 & 1.00 & 2.07 & 52.10 & 52.91 & 0.81 & 1.55 & -0.19 \\
\hline 30 & 43.72 & 44.68 & 0.96 & 2.20 & 47.44 & 48.23 & 0.79 & 1.67 & -0.17 \\
\hline 35 & 39.23 & 40.15 & 0.92 & 2.35 & 42.83 & 43.59 & 0.76 & 1.77 & -0.16 \\
\hline 40 & 34.78 & 35.65 & 0.88 & 2.53 & 38.28 & 39.01 & 0.73 & 1.91 & -0.15 \\
\hline 45 & 30.44 & 31.26 & 0.82 & 2.69 & 33.81 & 34.51 & 0.70 & 2.07 & -0.12 \\
\hline 50 & 26.25 & 27.02 & 0.77 & 2.93 & 29.46 & 30.13 & 0.67 & 2.27 & -0.10 \\
\hline 55 & 22.29 & 22.99 & 0.70 & 3.14 & 25.30 & 25.94 & 0.64 & 2.53 & -0.06 \\
\hline 60 & 18.54 & 19.18 & 0.64 & 3.45 & 21.35 & 21.95 & 0.60 & 2.81 & -0.04 \\
\hline 65 & 15.19 & 15.76 & 0.58 & 3.82 & 17.70 & 18.27 & 0.57 & 3.22 & -0.01 \\
\hline 70 & 12.15 & 12.67 & 0.52 & 4.28 & 14.37 & 14.91 & 0.54 & 3.76 & 0.02 \\
\hline 75 & 9.58 & 10.05 & 0.47 & 4.91 & 11.40 & 11.90 & 0.51 & 4.47 & 0.04 \\
\hline 80 & 7.42 & 7.89 & 0.46 & 6.20 & 8.83 & 9.34 & 0.50 & 5.66 & 0.04 \\
\hline \multicolumn{10}{|c|}{ Males } \\
\hline 0 & 63.25 & 65.52 & 2.27 & 3.59 & 70.70 & 72.00 & 1.30 & 1.84 & -0.97 \\
\hline 1 & 66.47 & 67.93 & 1.47 & 2.21 & 71.89 & 72.89 & 1.00 & 1.39 & -0.47 \\
\hline 5 & 64.24 & 65.39 & 1.16 & 1.81 & 68.62 & 69.51 & 0.89 & 1.30 & -0.27 \\
\hline 10 & 59.72 & 60.84 & 1.12 & 1.88 & 63.83 & 64.71 & 0.88 & 1.38 & -0.24 \\
\hline 15 & 55.00 & 56.11 & 1.11 & 2.02 & 59.00 & 59.87 & 0.87 & 1.47 & -0.24 \\
\hline 20 & 50.37 & 51.46 & 1.09 & 2.16 & 54.28 & 55.14 & 0.86 & 1.58 & -0.23 \\
\hline 25 & 45.86 & 46.93 & 1.07 & 2.33 & 49.66 & 50.51 & 0.85 & 1.71 & -0.22 \\
\hline 30 & 41.38 & 42.41 & 1.03 & 2.49 & 45.06 & 45.89 & 0.82 & 1.82 & -0.21 \\
\hline 35 & 36.95 & 37.94 & 0.99 & 2.68 & 40.52 & 41.32 & 0.80 & 1.97 & -0.19 \\
\hline 40 & 32.57 & 33.51 & 0.94 & 2.89 & 36.05 & 36.82 & 0.76 & 2.11 & -0.18 \\
\hline 45 & 28.33 & 29.21 & 0.88 & 3.11 & 31.67 & 32.39 & 0.73 & 2.31 & -0.15 \\
\hline 50 & 24.26 & 25.07 & 0.81 & 3.34 & 27.43 & 28.12 & 0.69 & 2.52 & -0.12 \\
\hline 55 & 20.44 & 21.18 & 0.73 & 3.57 & 23.41 & 24.06 & 0.65 & 2.78 & -0.08 \\
\hline 60 & 16.86 & 17.53 & 0.66 & 3.91 & 19.64 & 20.25 & 0.60 & 3.05 & -0.06 \\
\hline 65 & 13.72 & 14.31 & 0.60 & 4.37 & 16.22 & 16.79 & 0.57 & 3.51 & -0.03 \\
\hline 70 & 10.89 & 11.43 & 0.54 & 4.96 & 13.14 & 13.68 & 0.54 & 4.11 & 0.00 \\
\hline 75 & 8.54 & 9.03 & 0.49 & 5.74 & 10.38 & 10.89 & 0.51 & 4.91 & 0.02 \\
\hline 80 & 6.59 & 7.08 & 0.48 & 7.28 & 8.05 & 8.56 & 0.51 & 6.34 & 0.03 \\
\hline \multicolumn{10}{|c|}{ Females } \\
\hline 0 & 68.22 & 70.48 & 2.26 & 3.31 & 75.97 & 77.22 & 1.25 & 1.65 & -1.01 \\
\hline
\end{tabular}


Table 4 (continued)

\begin{tabular}{|c|c|c|c|c|c|c|c|c|c|}
\hline & 1990 & & & & 2017 & & & & \\
\hline & $e_{1990}$ & $e_{1990}^{-R I D}$ & $e_{1990}^{L}$ & $e_{1990}^{L} / e_{1990}(\%)$ & $e_{2017}$ & $e_{2017}^{-R I D}$ & $e_{2017}^{L}$ & $e_{2017}^{L} / e_{2017}(\%)$ & $e_{2017}^{L}-e_{1990}^{L}$ \\
\hline 1 & 71.24 & 72.67 & 1.43 & 2.01 & 77.04 & 77.96 & 0.92 & 1.19 & -0.51 \\
\hline 5 & 69.31 & 70.33 & 1.02 & 1.47 & 73.81 & 74.61 & 0.80 & 1.08 & -0.22 \\
\hline 10 & 64.76 & 65.73 & 0.97 & 1.50 & 69.03 & 69.80 & 0.78 & 1.13 & -0.19 \\
\hline 15 & 60.00 & 60.95 & 0.95 & 1.58 & 64.17 & 64.94 & 0.77 & 1.20 & -0.18 \\
\hline 20 & 55.33 & 56.25 & 0.92 & 1.66 & 59.39 & 60.14 & 0.75 & 1.26 & -0.17 \\
\hline 25 & 50.73 & 51.62 & 0.89 & 1.75 & 54.63 & 55.37 & 0.74 & 1.35 & -0.15 \\
\hline 30 & 46.15 & 47.00 & 0.85 & 1.84 & 49.90 & 50.62 & 0.72 & 1.44 & -0.13 \\
\hline 35 & 41.58 & 42.39 & 0.81 & 1.95 & 45.21 & 45.91 & 0.70 & 1.55 & -0.11 \\
\hline 40 & 37.04 & 37.81 & 0.77 & 2.08 & 40.57 & 41.25 & 0.68 & 1.68 & -0.09 \\
\hline 45 & 32.58 & 33.31 & 0.73 & 2.24 & 35.99 & 36.65 & 0.66 & 1.83 & -0.07 \\
\hline 50 & 28.24 & 28.93 & 0.69 & 2.44 & 31.50 & 32.14 & 0.64 & 2.03 & -0.05 \\
\hline 55 & 24.09 & 24.72 & 0.64 & 2.66 & 27.19 & 27.80 & 0.61 & 2.24 & -0.03 \\
\hline 60 & 20.12 & 20.71 & 0.59 & 2.93 & 23.01 & 23.59 & 0.58 & 2.52 & -0.01 \\
\hline 65 & 16.48 & 17.02 & 0.54 & 3.28 & 19.09 & 19.65 & 0.56 & 2.93 & 0.02 \\
\hline 70 & 13.17 & 13.66 & 0.49 & 3.72 & 15.47 & 16.00 & 0.53 & 3.43 & 0.04 \\
\hline 75 & 10.35 & 10.79 & 0.44 & 4.25 & 12.24 & 12.74 & 0.50 & 4.08 & 0.06 \\
\hline 80 & 7.99 & 8.42 & 0.44 & 5.51 & 9.42 & 9.91 & 0.49 & 5.20 & 0.05 \\
\hline
\end{tabular}

Data source: Global Burden of Disease Study (2017)

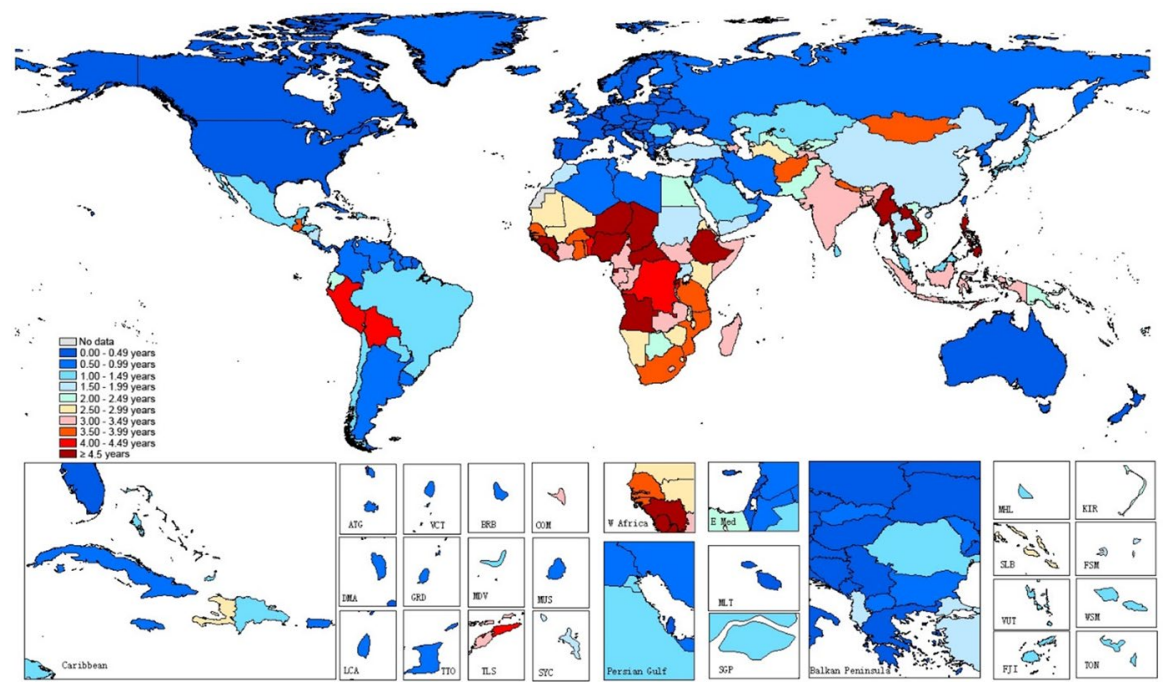

Fig. 4 Loss of LE due to RID at birth by country and territory in 1990. ATG Antigua and Barbuda, VCT Saint Vincent and the Grenadines, BRB Barbados, COM Comoros, DMA Dominica, GRD Grenada, MDV Maldives, MUS Mauritius, LCA Saint Lucia, TTO Trinidad and Tobago, TLS Timor-Leste, SYC Seychelles, MLT Malta, SGP Singapore, MHL Marshall Islands, KIR Kiribati, SLB Solomon Islands, FSM Federated States of Micronesia, VUT Vanuatu, WSM Samoa, FJI Fiji, TON Tonga. Data source: Global Burden of Disease Study (2017) 


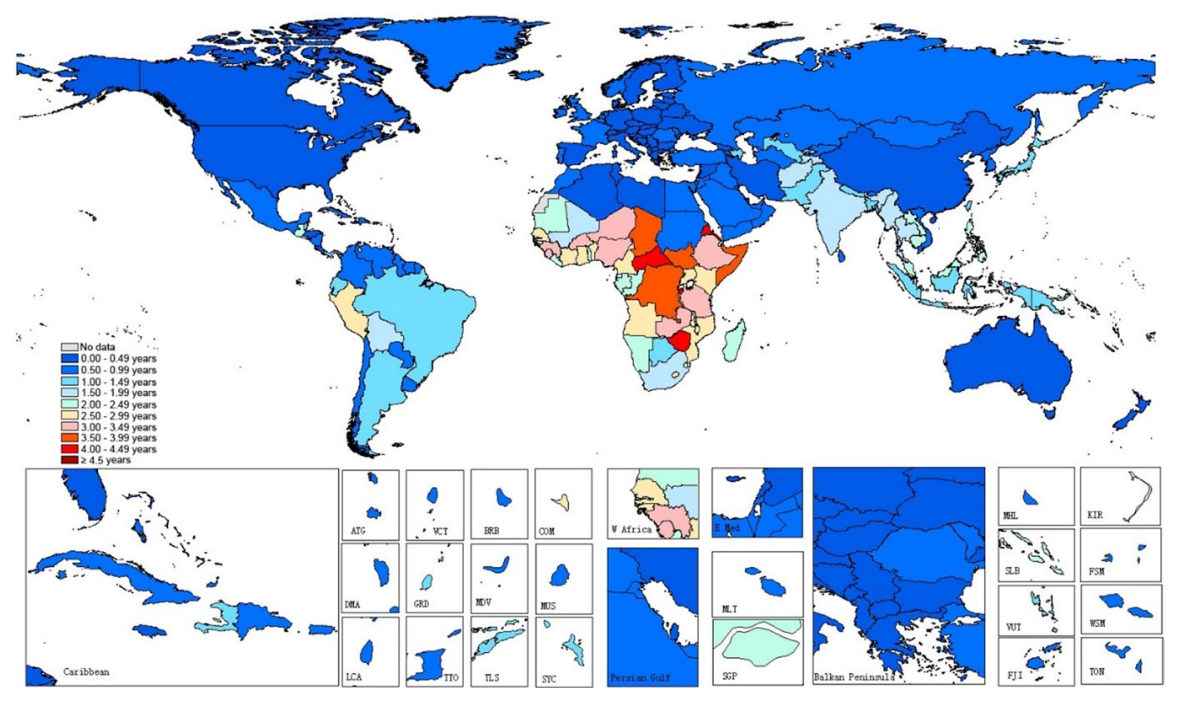

Fig. 5 Loss of LE due to RID at birth by country and territory in 2017. ATG Antigua and Barbuda, VCT Saint Vincent and the Grenadines, BRB Barbados, COM Comoros, DMA Dominica, GRD Grenada, MDV Maldives, MUS Mauritius, LCA Saint Lucia, TTO Trinidad and Tobago, TLS Timor-Leste, SYC Seychelles, MLT Malta, SGP Singapore, MHL Marshall Islands, KIR Kiribati, SLB Solomon Islands, FSM Federated States of Micronesia, VUT Vanuatu, WSM Samoa, FJI Fiji, TON Tonga. Data source: Global Burden of Disease Study (2017)

experienced a loss of LE due to RID of less than 1 year in 1990, middle/low income countries/territories (particularly those located in Sub-Saharan Africa, South Asia, and Southeast Asia) suffered a substantially larger loss of LE due to RID that year, with Nigeria (5.5 years); Niger (5.3 years); and Rwanda (5.3 years) experiencing the greatest losses of LE due to RID (for the rankings of country and territory for loss of LE due to RID at birth in 1990 and 2017 please refer to Appendix F). Most of the countries/territories with a relatively large loss of LE due to RID tended to have a GDP per capita lower than US\$5,000 in both 1990 and 2017, whereas most countries/territories that had a loss of LE due to RID of less than 0.5 years had a GDP per capita of more than US\$5,000 in both years (Fig. 6). The differences associated with geographic location for loss of LE due to RID and its association with GDP per capita imply that the disease burden of RID is closely related to the level of social and economic development, and that the unevenly spatially distributed global disease burden of RID is heavily borne by socioeconomically disadvantaged countries/ territories.

\section{Changes in loss of life expectancy due to respiratory infectious diseases during 1990-2017}

Analysis on the changes in loss of LE due to RID during the period 1990-2017 globally showed that global changes in loss of LE due to RID during the period 

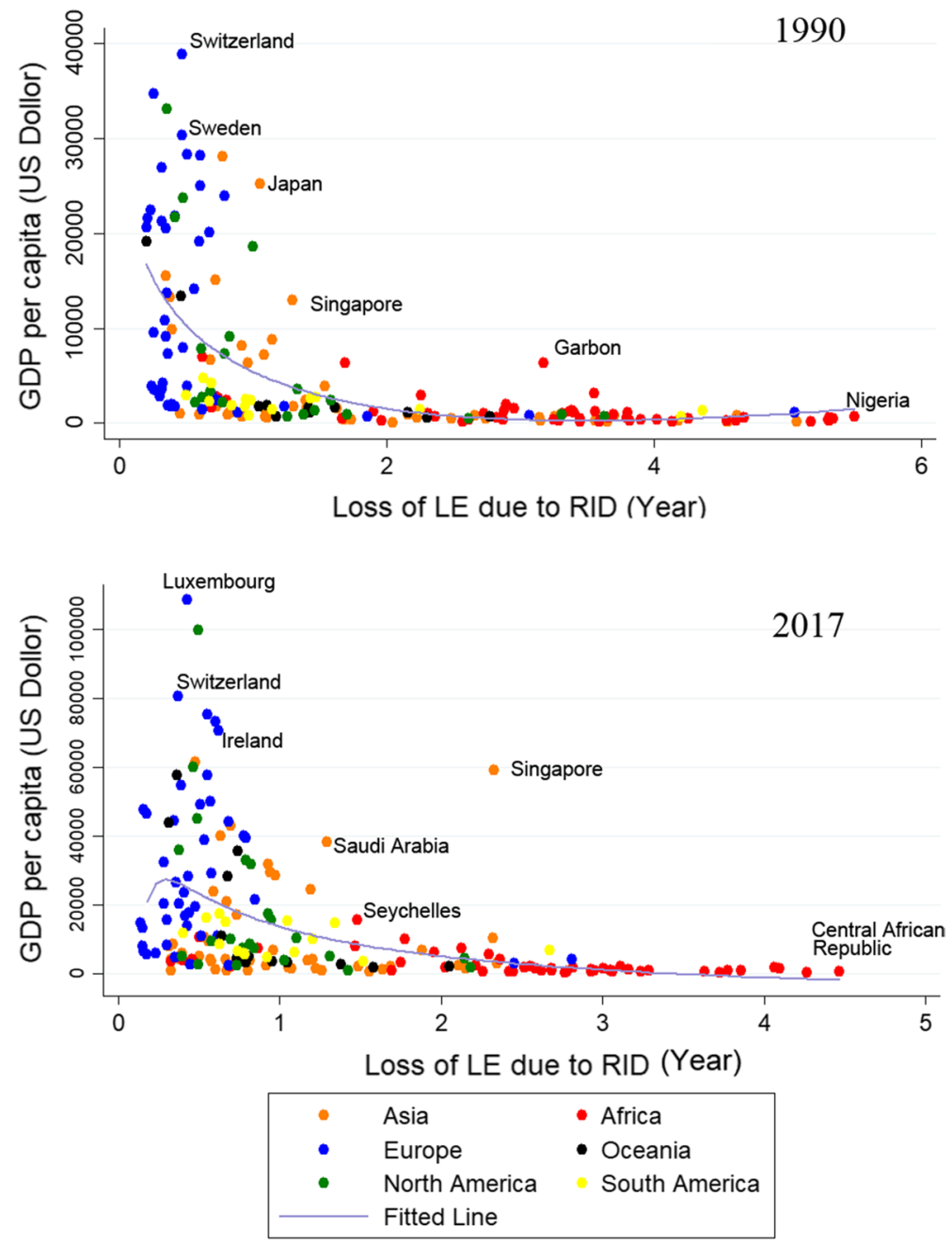

Fig. 6 Loss of LE due to RID and GDP Per Capita for 195 countries/territories in 1990 and 2017. The value of GDP per capita is adjusted based on the US dollar in 2020; the fitted line is estimated based on the fractional polynomial regression method. Data source: World Bank and Global Burden of Disease Study (2017)

1990-2017 were substantial and varied remarkably by age and among different countries/territories, as presented in Table 4 and Figs. 7 and 8.

Over the period 1990-2017, loss of LE due to RID decreased considerably but the decreases were uneven by age. Globally, loss of LE due to RID at birth decreased considerably from 2.26 years in 1990 to 1.29 years in 2017 (Table 4). Similar declines were also observed for most other age groups, suggesting that public health systems worldwide have made important advances in reducing RID disease burden over the past three decades. However, while most age groups experienced a decrease 


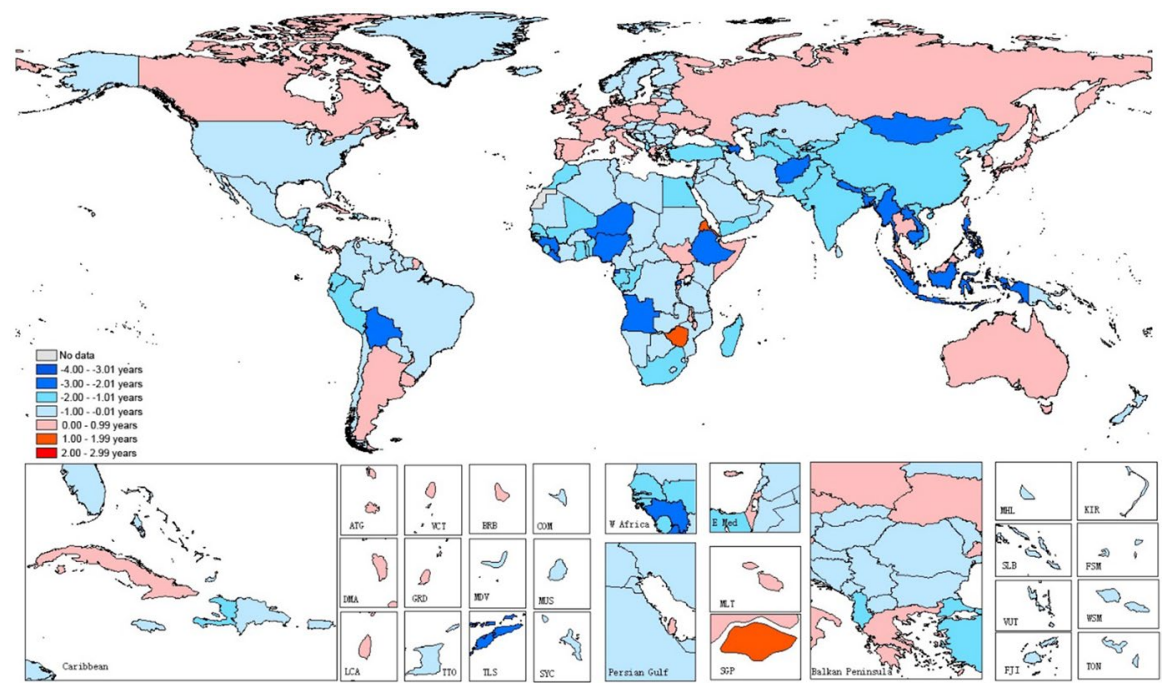

Fig. 7 Changes in loss of LE due to RID at birth $\left(e_{0,2017}^{L}-e_{0,1990}^{L}\right)$ by country and territory (1990-2017). $A T G$ Antigua and Barbuda, VCT Saint Vincent and the Grenadines, BRB Barbados, COM Comoros, DMA Dominica, GRD Grenada, MDV Maldives, MUS Mauritius, LCA Saint Lucia, TTO Trinidad and Tobago, TLS Timor-Leste, SYC Seychelles, MLT Malta, SGP Singapore, MHL Marshall Islands, KIR Kiribati, SLB Solomon Islands, FSM Federated States of Micronesia, VUT Vanuatu, WSM Samoa, FJI Fiji, TON Tonga. Data source: Global Burden of Disease Study (2017)

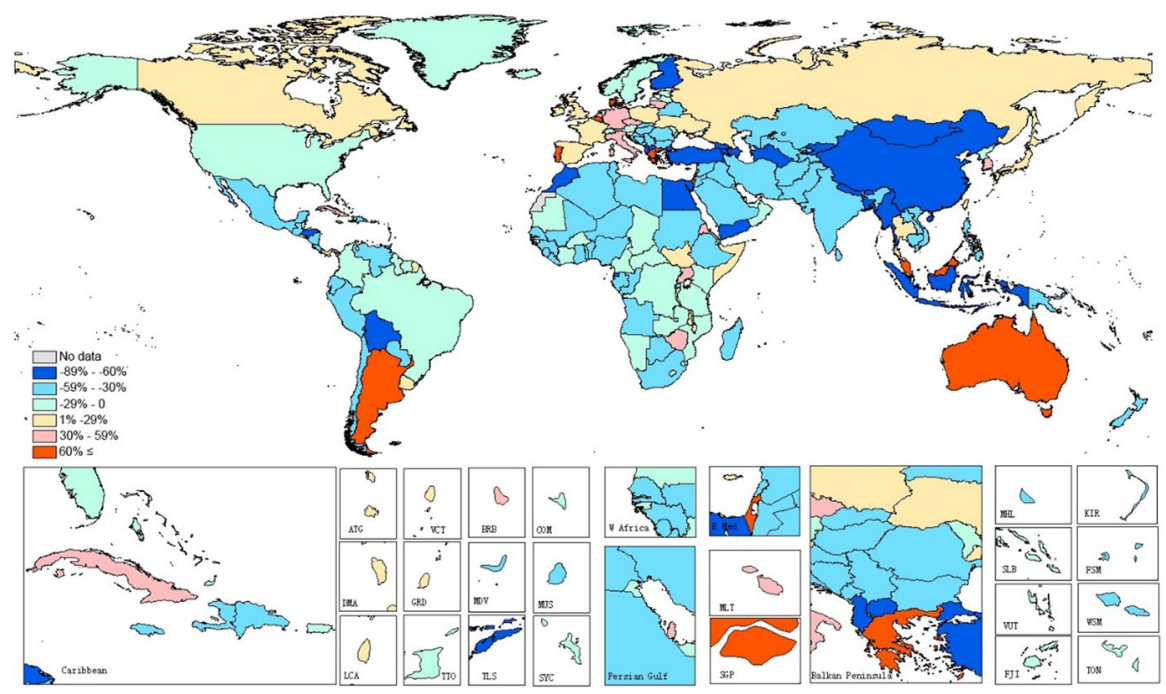

Fig. 8 Changes in loss of LE due to RID at birth (\%) $\left[\left(e_{0,2017}^{L}-e_{0,1990}^{L}\right) / e_{0,1990}^{L}\right]$ by country and territory (1990-2017). ATG Antigua and Barbuda, VCT Saint Vincent and the Grenadines, BRB Barbados, COM Comoros, DMA Dominica, GRD Grenada, MDV Maldives, MUS Mauritius, LCA Saint Lucia, TTO Trinidad and Tobago, TLS Timor-Leste, SYC Seychelles, MLT Malta, SGP Singapore, MHL Marshall Islands, KIR Kiribati, SLB Solomon Islands, FSM Federated States of Micronesia, VUT Vanuatu, WSM Samoa, FJI Fiji, TON Tonga. Data source: Global Burden of Disease Study (2017) 
in loss of LE due to RID, this change was not observed in many old age groups ${ }^{5}$ (Table 4), with populations aged 70 and older showing a slightly increased loss of LE due to RID during the period 1990-2017. Specifically, loss of LE due to RID globally was $0.52,0.47$, and 0.46 years for the age groups 70-74, 75-79, and 80 and older (respectively) in 1990, which increased to $0.54,0.51$, and 0.5 years respectively in 2017. The slight increases in loss of LE due to RID for people aged 70 and older suggest that while there has been global improvement in the overall reduction of loss of LE due to RID, such improvement has not been achieved for people aged older than 70. Older adults, who are particularly vulnerable to RID, have not benefited equally from the profoundly decreased threat of RID and are even bearing a greater loss of LE due to RID than they did nearly three decades ago.

In addition, the changes in loss of LE due to RID during the period 1990-2017 also vary substantially by geographic location. In contrast to the current geographic distribution of loss of LE due to RID, the changes in loss of LE due to RID over time are more favourable for middle/low income countries/territories than for countries/territories in the developed world. That is, despite the fact that middle/low income countries/territories had a greater loss of LE due to RID in 2017, most of these countries/territories experienced a considerable decrease in loss of LE due to RID during the period 1990-2017, and this decrease was significantly greater than that experienced in high income countries/territories (Figs. 7 and 8). For example, most countries/territories in Sub-Saharan Africa, South Asia, Southeast Asia, and South America have experienced varying decreases in loss of LE due to RID since 1990. The greatest decreases were seen in Equatorial Guinea (3.53 years); Laos (2.96 years); and Myanmar (2.92 years) (please refer to Appendix F for the rankings of country and territory regarding the change in loss of LE due to RID at birth during the period 1990-2017). In contrast, many high income countries/territories that have a low level of loss of LE due to RID, particularly those in Western Europe, showed an increase in loss of LE due to RID over the study period. For example, the United Kingdom, France, and Germany suffered an increase of 0.18 years $(29.36 \%)$, 0.12 years $(28.95 \%)$, and 0.11 years $(46.59 \%)$ in loss of LE due to RID, respectively, during the period 1990-2017. In addition, the following high income countries also saw an increase in loss of LE due to RID over the study period: Japan ( 0.24 years or $22.26 \%$ ); Australia (0.16 years or $77.73 \%)$; Canada (0.07 years or $15.92 \%)$; Belgium (0.34 years or $96.13 \%)$; and Greece $(0.22$ years or $85.41 \%)$. These findings demonstrate that while middle/low income countries/territories contribute importantly to the global decrease in disease burden of RID, high income countries/territories, despite their relatively low level of RID disease burden, are experiencing growing vulnerability of their populations to RID, suggesting that new challenges relating to the threat of RID have emerged for high income countries/territories in this new millennium in which highly rapid sociodemographic changes are occurring.

\footnotetext{
5 The definition of old age varies across countries given different socioeconomic development levels and cultural contexts. In this study, we use the UN-recommended threshold of old age (age 60) when referring old age.
} 


\section{Conclusion and discussion}

\section{Summary of results}

Loss of LE due to RID is an important indicator in measuring the health impacts of RID and has underlying implications in monitoring and controlling for the disease burden of RID. This study is the first attempt to analyse loss of LE due to RID in 195 countries/territories during the period 1990-2017, and it performs a comprehensive examination of the life-shortening effect of RID at the global and country/ territory levels. The study explores and compares the levels of loss of LE due to RID by age, gender, and geographic location, as well as investigates changing trends in these levels over time. Corresponding characteristics and changes in ratio of loss of LE due to RID in remaining LE are also investigated. The results demonstrate that the loss of LE due to RID was 1.29 years globally in 2017 and the effect of RID in determining lifespan varied remarkably by age, gender, and countries/territories, with men, elderly people, and populations in middle/low income countries/ territories bearing a disproportionately high loss of LE due to RID. The study also found that during the period 1990-2017, the loss of LE due to RID decreased overall but exhibited increasing trends for populations older than age 70 globally and for populations in many high income countries/territories. These results provide a more nuanced understanding on the inadequately understood changing disease burden of RID and shed light on the challenges that will be posed by RID on population and public health in the future.

\section{Discussion of results}

The results show that the world has made tremendous progress in reducing the loss of LE due to RID since 1990, with loss of LE due to RID at birth globally decreasing from 2.26 to 1.29 years from 1990 to 2017 (i.e., by 0.97 years or 43\%). The decrease was particularly significant for populations under age 70 and for those in middle/low income countries/territories, which experienced a decrease of loss of LE due to RID both in years and in proportion. The overall decrease of loss of LE due to RID globally is supported by the theory of epidemiological transition arguing for a generally decreased disease burden of infectious diseases and is also in line with previous studies reporting a declining trend in disease burden of RID worldwide (Murray et al., 2012; Nair et al., 2011). The overall decreased loss of LE due to RID demonstrated in this study provides new evidence for the ongoing declining trend in disease burden of RID and highlights the importance of executed measures in controlling for RID over the past three decades. However, the study also demonstrates that despite the overall declining trend in disease burden of RID, RID are still a major threat to human health, remaining the deadliest type of infectious diseases and the fourth leading cause of death worldwide. The currently on-going COVID-19 is a such example of this profound impact. Hence, it is unwise and also dangerous to be overly complacent about the achieved progress in RID prevention and control. 
Greater efforts are needed to reinforce and improve the established system to further decrease the mortality from RID, even after the COVID-19 crisis.

The results also demonstrate that disease burden of RID distributes unevenly worldwide and is closely related to the level of socioeconomic development among countries/territories. While loss of LE due to RID stayed lower than 1 year in high income countries/territories, such as those in Europe, North America (excluding Central America and the Caribbean), and Australasia, where countries/territories tend to have a high level of socioeconomic development, it was generally higher than 1.5 years in many parts of middle/low income countries/territories, particularly those located in Sub-Saharan Africa, South Asia, Southeast Asia, and South America, where socioeconomic development lags behind the rest of world (United Nations, 2019a). Thus, socioeconomic development level tends to be negatively associated with the disease burden of RID and the disproportionately high disease burden of RID in middle/low income countries/territories may be primarily attributed to the socioeconomic disadvantages in these countries/territories. This is in line with previous studies finding a high disease burden in the developing world and that accessibility to good-quality sanitation systems and affordability of treatment are the primary causes for the high prevalence of infectious diseases in many developing countries/territories (Stevens, 2004). Thus, although most middle/low income countries/territories have experienced a substantial decrease of loss of LE due to RID over the past nearly three decades, reducing the disease burden of RID in the developing world remains a major challenge for further control of RID, and should be prioritised in the global agenda in cooperation and collaboration to achieve RID control and prevention.

Another important finding of this study is that in contrast to the global declining trend in disease burden of RID, many high income countries/territories (e.g., most Western European countries/territories, Japan, South Korea, Canada, and Australia) experienced a resurgence in disease burden of RID, with their loss of LE due to RID showing an upward trend during the period 1990-2017. Although these increases of loss of LE due to RID tended to be small (i.e., generally lower than 0.3 years), the trend has the crucial implication that despite their remarkable success in controlling RID in the twentieth century, high income countries/territories are facing new vulnerability and challenges in RID control and prevention in the new millennium. This puzzling increase of loss of LE due to RID in these high income countries/territories may be explained by a series of rapid social and demographic changes that have occurred in the past several decades.

First and most importantly, populations in most high income countries/territories are highly aged, seeing a large and still growing proportion of their populations entering old age, which contributes to an increasing number of people susceptible to RID and an expanding size of the population sustaining the transmission of RID because of the high susceptibility to RID of elderly people. Additionally, some changes that accompany population ageing also contribute to an increased disease burden of RID. For example, growing utilisation of institutional care and nursing home care can facilitate the spread of RID because institutions and nursing homes are an ideal environment for the transmission of RID due to communal living conditions and residents' frequent contact with visitors, staff, and other residents 
(Garibaldi, 1999; Strausbaugh et al., 2003). Other characteristics of institutions and nursing homes, such as clustering of residents in a confined living arrangement, overcrowding of the accommodation, encouragement of group activities, poor compliance with routine infections prevention and control practices due to understaffing, use of unprofessional staff and high rate of employee turnout, all favour the spread of RID (Garibaldi et al., 1981; Matheï et al., 2007). The tragically high mortality rate in aged care facilities during the COVID-19 pandemic in many high income countries/territories (e.g. in Australia, 60\% of deaths of COVID-19 have occurred in aged care facilities) is strong evidence for the high risk of RID transmission in aged care facilities (Australian Department of Health, 2020; Bedford et al., 2020). Even though conventionally RID are seen as 'diseases of poverty', the empirical results from this study and observations from the current COVID-19 crisis suggest that RID could also be seen as 'diseases of the aged'. Moreover, other sociodemographic changes, such as the prevalence of children in day care and the increasing number of people travelling globally, can also contribute to a heightened disease burden of RID in many countries/territories (Louhiala et al., 1995; Pavia, 2007). For example, up to $70 \%$ of international travellers report having contracted illnesses after the travel. Among these reported illnesses, some types of RID (e.g. influenza, tuberculosis and legionella) can cause serious discomfort and illness for international travellers, and may also be transmitted by these travellers to their home populations (Habib \& Behrens, 2000; Ryan et al., 2002).

Another key finding of this study is that elderly people are particularly susceptible to RID and suffered an increased loss of LE due to RID during the period 1990-2017. For age groups older than 70, increase in loss of LE due to RID from 1990 to 2017 varied from $0.02-0.04$ years, indicating that RID remain particularly deadly for elderly people despite advances in medical technology over the past several decades. The high and ever-increasing vulnerability of elderly people to RID is consistent with some previous studies showing a rising threat of RID to elderly populations (Byng-Maddick \& Noursadeghi, 2016; Corrêa et al., 2017; Haq \& McElhaney, 2014), and corresponds to recent studies that report particularly high mortality and morbidity caused by the COVID-19 among the elderly (Wu et al., 2020) (Appendix C). The high vulnerability to RID among the elderly may be primarily attributed to biological changes with age.

First, as age increases, the efficiency of the innate and adaptive immune systems declines irreversibly, which reduces respiratory immune responses to common RID (Gardner, 1980; Haq \& McElhaney, 2014) and curtails the effect of vaccines for RID in stimulating the cell-mediated immune function that plays a key role in immune system (Yamaya et al., 2002). Second, organs of the respiratory system, particularly the lungs, suffer a series of degenerative changes with age, such as decreased exchange surface area, reduced lung elasticity and respiratory muscle strength, and loss of supporting tissue for peripheral airways (Dyer, 2012; Janssens et al., 1999). Consequently, constant exposure of the respiratory tract to pathogens and allergens, which may be not harmful to younger people, will lead to RID among the elderly (Haq \& McElhaney, 2014). Third, co-existing chronic diseases in later life can induce RID and complicate the symptoms and treatment of RID (Gardner, 1980). For example, cerebrovascular diseases, 
atherosclerosis, and chronic obstructive lung diseases predispose patients to respiratory tract infections and exacerbate the outcomes of RID (Dhar et al., 1976). Fourth, timely detection and treatment of RID among the elderly are difficult in general because of the factors of overlapping symptoms of RID with agerelated illnesses, RID's unique clinic presentation in old age, and the difficulty of obtaining an accurate medical history (Haq \& McElhaney, 2014). Recent research indicates that a substantial part of the differences in case fatality rate of COVID-19 among different countries is explained by the age composition of detected infections of COVID-19, in which elderly people have a disproportionately high representation (Dudel et al., 2020). The high vulnerability of elderly people to RID needs to attract increased attention from researchers, health providers, and policymakers, given that the world will experience dramatic population ageing throughout the twenty-first century, which may lead to a resurge in the disease burden of RID.

The results from this study also demonstrate that men bear a higher mortality from RID and suffer a greater loss of LE due to RID than do women at all ages, suggesting that men are more vulnerable to RID. This corresponds to previous studies that have found that men are more susceptible to most respiratory diseases and related morbidity, such as pneumonia (Gannon et al., 2004), chronic obstructive pulmonary diseases (Chapman et al., 2001), Hantavirus pulmonary syndrome (Casoni et al., 2003), and the current COVID-19 (Wu et al., 2020). For example, men's case fatality rate of COVID-19 is more than two times that of women's (Jin et al., 2020; Wu et al., 2020). Men's greater vulnerability to RID may be primarily explained by gender differences related to biological mechanism and factors of behaviour and occupation. For example, sex steroid hormones have varying effects on immune response to infections, with testosterone generally exerting a detrimental effect on the immune system, such as reducing the production of antibodies and decreasing the expressions of specific receptors, while estrogen tends to elevate immune responses (McClelland \& Smith, 2011). In addition, men generally have a smaller airway relative to lung size and greater respiratory resistance than women of a similar height, and these two factors are associated with an elevated possibility of viral infections of the respiratory tract (Casoni et al., 2003; Wainwright, 2010). Moreover, smoking, which is associated with a low level of lung function and a higher rate of presentations of respiratory symptoms, is more prevalent among men (Holmen et al., 2002). Likewise, men have a greater representation in occupations (e.g. food industry workers, wood workers, and industrial workers) that are associated with an increased risk of respiratory illness (Nathell et al., 2000). Further, men are less likely to adopt protective behaviour, such as frequent hand washing, wearing a face mask, and avoidance of public transport, during a pandemic or epidemic, increasing their likelihood of being exposed to RID (Moran \& Del Valle, 2016). The gender difference in vulnerability of RID implies that gender plays a crucial role in disease burden of RID and should be carefully considered in RID prevention and control, with targeted efforts being enacted to reduce male vulnerability to RID. 


\section{Policy implications}

The results from this study have several important implications for policies and practices aiming to prevent and control RID. First, it is vital to remain vigilant over the ever-changing threat of RID, which, despite the substantial declining trend in mortality rates over the past several decades, still impose a serious challenge to global public health. Strengthened national and international surveillance of changing patterns of the disease burden of RID and higher levels of global cooperation and collaboration are needed to effectively and efficiently recognise and respond to emerging RID amid rapid sociodemographic changes. New efforts in developing strategies and programmes to further control and eradicate RID are also needed to preserve and extend the already achieved successes in RID prevention and control. The experience and lessons from fighting COVID-19 demonstrate that an efficient and effective surveillance system is the cornerstone in controlling the spread of RID and that enhanced global cooperation is essential in constraining major RID pandemics (Lee et al., 2020; Liu et al., 2020; Momtazmanesh et al., 2020). Second, significant support and resources are required to improve RID prevention and control in the developing world, where countries/territories bear a disproportionately high disease burden of RID. This is of vital importance for global disease control of RID, in that populations in the developing world represent a rising proportion of the global population and that the high prevalence of RID in the developing world may spread to the developed world via increasing migration and international travel. In addition, efforts to ensure disease control of RID for the developing world would be more effective and sustainable if based on simultaneous socioeconomic development. Third, while special awareness is advised for policymakers and health care providers in middle/low income countries/territories, policymakers and health care providers in high income countries/territories must also keep a close watch on trends in RID and prepare in advance for a resurgence in the disease burden of RID in such locations. It is suggested to enhance the capacity of health care systems to address the special needs of older RID patients and promote research to deepen understanding of elderly people's vulnerability to RID and stimulate development of new therapies and treatments for the elderly. The disproportionately high prevalence and mortality among elderly in the current COVID-19 pandemic once again indicates the grave threat of RID to the elderly population and the vital importance in taking preventative measures in protecting elderly population, which is particularly needed given the profound population ageing in many societies. Fourth, measures to reduce male vulnerability to RID are suggested, such as launching campaigns for tobacco control and encouraging protective behaviours during epidemics and pandemics for both genders.

\section{Limitations}

There are several limitations in this study that need to be acknowledged. First, the study investigates the patterns of and changes in loss of LE due to RID, considering 
RID as one cause of death but not exploring the differences between different types of RID. Given that different types of RID differ in epidemiology, the results of this study may vary for different types of RID. Second, this study examines the mortality caused by RID, but has not explored the morbidity related to RID, so the results only reflect the effect of RID on lifespan but not on quality of life. Future research should also explore changing disease burden for different types of RID and the effect and patterns of RID on quality of life to generate a deeper understanding of the disease burden of RID. Third, although this study finds that loss of LE due to RID increased over time in some high income countries/territories, which might be indirectly affected by the ongoing population ageing in these countries/territories, as discussed before, this study has not quantified how and to what extent the trend of population ageing affects the changes of loss of LE due to RID over time. This study also has not investigated and compared the differences of such effects across countries/territories. Fourth, although cause-eliminated life expectancy provides an easy way to summarise the disease burden of diseases and injuries, it has important limitations. For example, deleting diseases and injuries at young age contributes greater to gains in LE than that at old age; however, this is unable to be detected by using cause-eliminated life expectancy. Fifth, GDP per capita, though frequently used in measuring the socioeconomic development and prosperity of a country, has some important limitations. For example, GDP per capita is unable to measure the level of socioeconomic inequality, the wellbeing of a country's inhabitants, and the sustainability of development model of a country. Other indicators, such as Gini coefficient and human development index, could be considered for future research in exploring the relationship between the disease burden of RID and level of socioeconomic development.

This study provides the first attempt to analyse the effect of RID on lifespan in 195 countries/territories over a period of almost three decades. This study is unique given its originality and comprehensiveness in examining the changing disease burden of RID at the global level and for countries/territories. The results from this study have important implications for improving and advancing current RID prevention and control, and also shed light on policies and practices that can be implemented to better address the challenges of the current pandemic of COVID-19 and future RID emergencies.

\section{Appendices}

\section{Appendix A Countries/territories by income, 2017}

\section{High income countries/territories}

Andorra, Antigua and Barbuda, Australia, Austria, Bahrain, Barbados, Belgium, Bermuda, Brunei, Canada, Chile, Croatia, Cyprus, Czech Republic, Denmark, Estonia, Faeroe Islands, Finland, France, Germany, Greece, Greenland, Guam, Hungary, Iceland, Ireland, Israel, Italy, Japan, Kuwait, Latvia, Lithuania, Luxembourg, Malta, Netherlands, New Zealand, Northern Mariana Islands, Norway, Oman, Poland, 
Portugal, Puerto Rico, Qatar, Saudi Arabia, Seychelles, Singapore, Slovakia, Slovenia, South Korea, Spain, Sweden, Switzerland, Taiwan (Province of China), The Bahamas, Trinidad and Tobago, United Arab Emirates, United Kingdom, United States, Uruguay, Virgin Islands (USA).

\section{Upper-middle income countries/territories}

Albania, Algeria, American Samoa, Angola, Argentina, Azerbaijan, Belarus, Belize, Bosnia and Herzegovina, Botswana, Brazil, Bulgaria, China, Colombia, Costa Rica, Cuba, Dominica, Dominican Republic, Ecuador, Equatorial Guinea, Fiji, Gabon, Georgia, Grenada, Guyana, Iran, Iraq, Jamaica, Jordan, Kazakhstan, Lebanon, Libya, Macedonia, Malaysia, Maldives, Marshall Islands, Mauritius, Mexico, Montenegro, Namibia, Panama, Paraguay, Peru, Romania, Russian Federation, Saint Lucia, Saint Vincent and the Grenadines, Serbia, South Africa, Suriname, Thailand, Turkey, Turkmenistan, Venezuela.

\section{Lower-middle income countries/territories}

Armenia, Bangladesh, Bhutan, Bolivia, Cambodia, Cameroon, Cape Verde, Congo, Cote d'Ivoire, Djibouti, Egypt, El Salvador, Ghana, Guatemala, Honduras, India, Indonesia, Kenya, Kiribati, Kyrgyzstan, Laos, Lesotho, Mauritania, Moldova, Mongolia, Morocco, Myanmar, Nicaragua, Nigeria, Pakistan, Palestine, Papua New Guinea, Philippines, Samoa, Sao Tome and Principe, Solomon Islands, Sri Lanka, Sudan, Swaziland, Syria, Tajikistan, Timor-Leste, Tonga, Tunisia, Ukraine, Uzbekistan, Vanuatu, Vietnam, Yemen, Zambia.

\section{Low income countries/territories}

Afghanistan, Benin, Burkina Faso, Burundi, Central African Republic, Chad, Comoros, Democratic Republic of the Congo, Eritrea, Ethiopia, Guinea, GuineaBissau, Haiti, Liberia, Madagascar, Malawi, Mali, Mozambique, Nepal, Niger, North Korea, Rwanda, Senegal, Sierra Leone, Somalia, South Sudan, Tanzania, The Gambia, Togo, Uganda, Zimbabwe. 


\section{Appendix B Changes in population age structure, globally and by country} income, 1990-2017

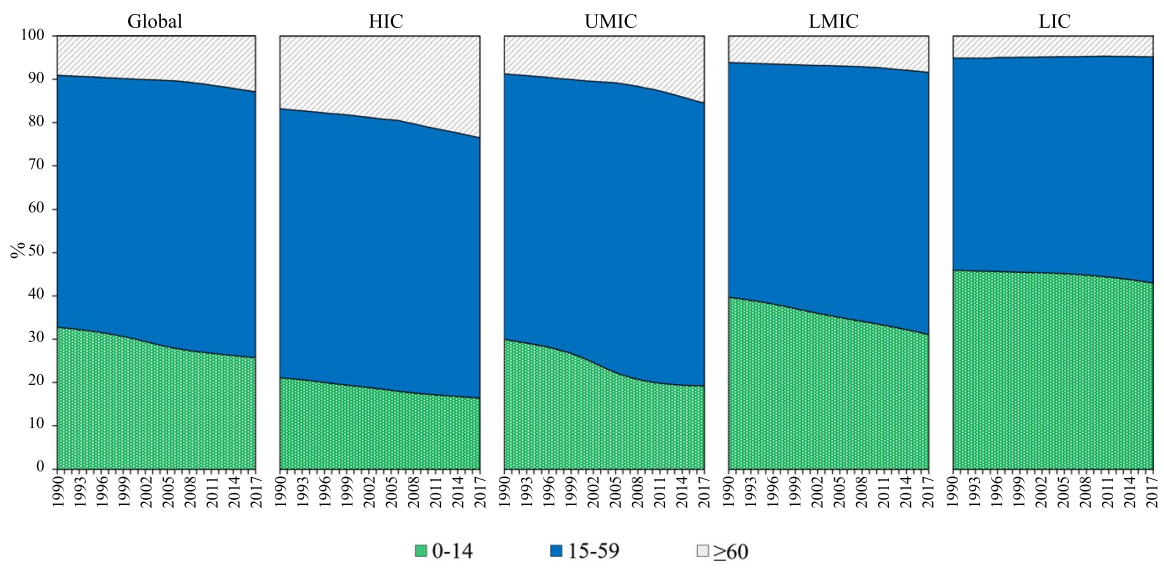

Note: 'HIC' refers to 'high income countries/territories', 'UMIC' refers to 'uppermiddle income countries/territories', 'LMIC' refers to 'lower-middle income countries/territories' and 'LIC' refers to 'low income countries/territories'. Data source: Global Burden of Disease Study (2017)

\section{Appendix C Case fatality rate of COVID-19 in selected countries and regions}

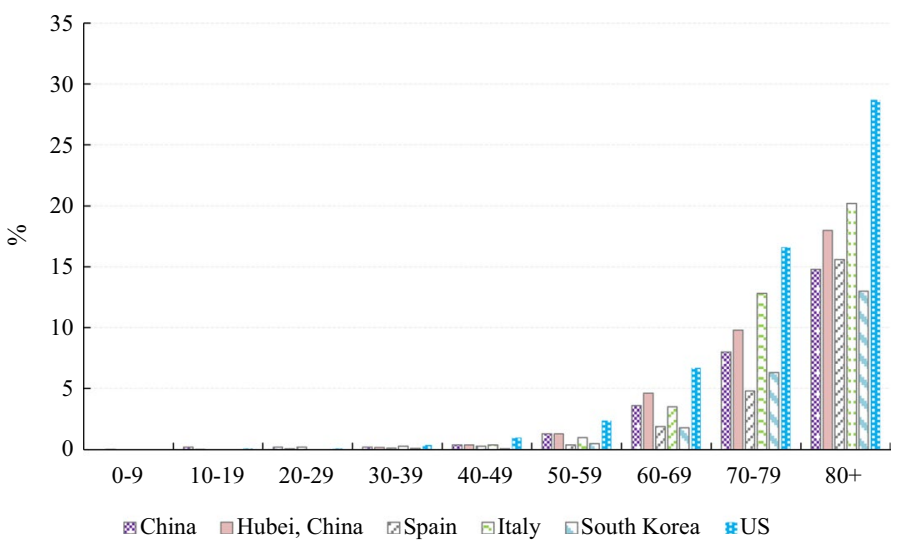

Source: Data for China was as of 17 February 2020 and sourced from the study of the Chinese Center for Disease Control and Prevention (2020); data for Hubei, 
China was as of 11 February 2020 and sourced from the research of Hauser et al. (2020); data for Spain was as of 24 March 2020 and obtained from the Health Minister of Spain (2020); data for Italy was as of 17 March 2020 and obtained from the study of Onder et al. (2020); data for South Korea was as of 24 March 2020 and sourced from Soneji et al. (2021); and data for the US was as of 30 May 2020 and sourced from Centers for Disease Control and Prevention (2020). Case fatality rate is defined as the proportion of deaths assigned to a specific cause during a given time interval. In this study, case fatality rate of COVID-19 is calculated by the formula $\frac{\text { Number of deaths due to COVID-19 }}{\text { Number of confirmed cases of COVID-19 }} \times 100 \%$. Please be noted that the case fatality rate of COVID-19 is affected by the varying testing capacity across countries and might be underestimated in countries or territories with a low capacity to test the virus.

\section{Appendix D Construction of life tables and RID-eliminated life tables}

Life tables were constructed following the method proposed by Chiang (1979), outlined as follows.

Let ${ }_{n} m_{x}$ represent the mortality rate for the age group $(x, x+n)$, where $x$ denotes age and $n$ denotes age interval, and ${ }_{n} a_{x}=\frac{n}{2}$, where ${ }_{n} a_{x}$ is the average fraction of the age group $(x, x+n)$ lived by individuals dying at any age included in the age group.

First, probability of death ${ }_{n} q_{x}$ can be computed as below:

$$
{ }_{n} q_{x}=\frac{n *{ }_{n} m_{x}}{1+\left(1-{ }_{n} a_{x}\right) * n *{ }_{n} m_{x}} .
$$

For the highest age group,

$$
{ }_{\infty} q_{80}=1 \text {. }
$$

Based on ${ }_{n} q_{x}$, indicators of ${ }_{n} p_{x},{ }_{n} d_{x}$ and ${ }_{n} l_{x}$, representing the probability of survival, the number of deaths, and the number of surviving persons for the age group $(x, x+n)$, respectively, can be obtained through the following equations:

$$
\begin{aligned}
& { }_{n} p_{x}=1-{ }_{n} q_{x}, \\
& { }_{n} d_{x}=l_{x}-{ }_{n} q_{x}, \\
& l_{x+n}=l_{x}-{ }_{n} d_{x} .
\end{aligned}
$$

For age 0,

$$
l_{0}=100,000
$$

Then, person-years lived between age $x$ and $x+n,{ }_{n} L_{x}$, can be computed by Eq. (7): 


$$
{ }_{n} L_{x}=n * l_{x+n}+{ }_{n} a_{x} *{ }_{n} d_{x}
$$

For the highest age group,

$$
{ }_{\infty} L_{80}=\frac{l_{80}}{{ }_{\infty} m_{80}} .
$$

Person-years lived above age $x, T_{x}$, is computed as follows:

$$
{ }_{n} T_{x}=\sum_{i=x}^{\infty}{ }_{n} L_{x} .
$$

Finally, LE at age $x$ can be estimated by the following equation:

$$
e_{x}=\frac{T_{x}}{l_{x}} .
$$

The study followed the method of Smith (1985) to construct RID-eliminated life tables, beginning with the computation of the probability of survival, ${ }_{n} p_{x}^{-R I D}$, for the age group $(x, x+n)$ if RID are eliminated:

$$
{ }_{n} p_{x}^{-R I D}={ }_{n} p_{x-} n R_{x},
$$

where ${ }_{n} R_{x}$ refers to the ratio of the number of deaths due to causes other than RID to the total number of deaths for the age group $(x, x+n)$ and

$$
{ }_{n} R_{x}=\frac{{ }_{n} D_{x}^{t}-{ }_{n} D_{x}^{R I D}}{{ }_{n} D_{x}^{t}},
$$

where ${ }_{n} D_{x}^{t}$ is the total number of deaths for the age group $(x, x+n)$ and ${ }_{n} D_{x}^{R I D}$ is the number of deaths due to RID in the same age group.

The number of surviving persons at age $x+n$ if RID are eliminated, $l_{x+n}^{-R I D}$, are computed as below:

$$
l_{x+n}^{-R I D}=l_{x}^{-R I D} *{ }_{n} p_{x}^{-R I D} .
$$

Based on $l_{x+n}^{-R I D}$, RID-eliminated person-years lived for the age group $(x, x+n)$, ${ }_{n} L_{x}^{-R I D}$, can be computed through Eq. 14:

$$
{ }_{n} L_{x+n}^{-R I D}=n * l_{x+n}^{-R I D}+{ }_{n} a_{x} *\left(l_{x}^{-R I D}-l_{x+n}^{-R I D}\right) .
$$

For the highest age group,

$$
{ }_{\infty} L_{80}^{-R I D}=\frac{l_{80}^{-R I D}}{\infty_{80}^{-R I D}},
$$

where ${ }_{\infty} m_{80}^{-R I D}$ is the mortality for the highest age group if RID are eliminated. 
Finally, $T_{x}^{-R I D}$ and $e_{x}^{-R I D}$, representing person-years lived above age $x$ if RID are eliminated, and the corresponding RID-eliminated LE at age $x$, can be obtained following the equations as follows:

$$
\begin{gathered}
T_{x}^{-R I D}=\sum_{i=x}^{\infty}{ }_{n} L_{x}^{-R I D}, \\
e_{x}^{-R I D}=\frac{T_{x}^{-R I D}}{l_{x}^{-R I D}} .
\end{gathered}
$$

Loss of LE due to RID at age $x$ is obtained as below:

$$
e_{x}^{L}=e_{x}^{-R I D}-e_{x}
$$

\begin{tabular}{|c|c|c|c|c|c|c|c|c|c|c|c|c|}
\hline \multirow[t]{3}{*}{ Country/territory } & \multicolumn{6}{|l|}{1990} & \multicolumn{6}{|l|}{2017} \\
\hline & \multicolumn{2}{|c|}{$\begin{array}{l}\text { Both } \\
\text { genders }\end{array}$} & \multicolumn{2}{|l|}{ Male } & \multicolumn{2}{|c|}{ Female } & \multicolumn{2}{|c|}{$\begin{array}{l}\text { Both } \\
\text { genders }\end{array}$} & \multicolumn{2}{|l|}{ Male } & \multicolumn{2}{|c|}{ Female } \\
\hline & $\overline{e_{0}}$ & $e_{0}^{L}$ & $e_{0}$ & $e_{0}^{L}$ & $e_{0}$ & $e_{0}^{L}$ & $\overline{e_{0}}$ & $e_{0}^{L}$ & $e_{0}$ & $e_{0}^{L}$ & $e_{0}$ & $e_{0}^{L}$ \\
\hline Afghanistan & 48.3 & 3.6 & 49.0 & 3.3 & 47.7 & 3.9 & 62.6 & 1.6 & 62.8 & 1.5 & 62.4 & 1.6 \\
\hline Albania & 73.9 & 1.9 & 70.2 & 1.7 & 78.3 & 2.0 & 78.7 & 0.4 & 75.0 & 0.4 & 83.4 & 0.3 \\
\hline Algeria & 72.1 & 0.8 & 70.6 & 0.8 & 73.7 & 0.8 & 79.0 & 0.5 & 78.3 & 0.5 & 79.6 & 0.4 \\
\hline American Samoa & 71.0 & 0.8 & 67.8 & 0.8 & 75.2 & 0.9 & 72.0 & 0.6 & 70.2 & 0.6 & 73.8 & 0.7 \\
\hline Andorra & 79.9 & 0.8 & 76.6 & 0.6 & 84.4 & 1.0 & 82.9 & 0.8 & 80.7 & 0.7 & 85.5 & 0.9 \\
\hline Angola & 47.8 & 5.1 & 45.6 & 5.0 & 50.5 & 5.0 & 64.3 & 2.8 & 61.8 & 3.1 & 66.9 & 2.4 \\
\hline Antigua and Barbuda & 74.6 & 0.8 & 71.0 & 0.7 & 78.4 & 0.9 & 77.4 & 0.9 & 76.0 & 1.0 & 78.8 & 0.9 \\
\hline Argentina & 72.6 & 0.6 & 69.1 & 0.6 & 76.3 & 0.6 & 76.8 & 1.3 & 73.7 & 1.3 & 79.9 & 1.4 \\
\hline Armenia & 70.0 & 1.1 & 66.6 & 1.1 & 73.3 & 1.1 & 75.8 & 0.4 & 72.5 & 0.4 & 78.8 & 0.3 \\
\hline Australia & 77.2 & 0.2 & 74.0 & 0.2 & 80.5 & 0.2 & 82.8 & 0.4 & 80.6 & 0.3 & 85.0 & 0.4 \\
\hline Austria & 76.0 & 0.2 & 72.5 & 0.2 & 79.2 & 0.2 & 82.0 & 0.2 & 79.8 & 0.2 & 84.1 & 0.1 \\
\hline Azerbaijan & 67.5 & 3.3 & 63.5 & 3.3 & 71.4 & 3.3 & 70.6 & 1.2 & 66.8 & 1.1 & 75.2 & 1.3 \\
\hline Bahrain & 70.4 & 0.4 & 69.4 & 0.4 & 71.8 & 0.4 & 80.8 & 0.6 & 80.0 & 0.6 & 81.8 & 0.6 \\
\hline Bangladesh & 58.3 & 3.2 & 57.4 & 3.3 & 59.7 & 2.9 & 73.1 & 1.1 & 71.7 & 1.1 & 74.6 & 1.0 \\
\hline Barbados & 74.1 & 0.6 & 71.5 & 0.6 & 76.5 & 0.6 & 77.2 & 0.9 & 75.6 & 0.9 & 78.6 & 0.9 \\
\hline
\end{tabular}

\section{Appendix E LE $\left(e_{0}\right)$ and loss of LE due to RID at birth $\left(e_{0}^{L}\right)$ in 1990 and 2017 by country and territory}




\begin{tabular}{|c|c|c|c|c|c|c|c|c|c|c|c|c|}
\hline \multirow[t]{3}{*}{ Country/territory } & \multicolumn{6}{|c|}{1990} & \multicolumn{6}{|c|}{2017} \\
\hline & \multicolumn{2}{|c|}{$\begin{array}{l}\text { Both } \\
\text { genders }\end{array}$} & \multicolumn{2}{|l|}{ Male } & \multicolumn{2}{|c|}{ Female } & \multicolumn{2}{|c|}{$\begin{array}{l}\text { Both } \\
\text { genders }\end{array}$} & \multicolumn{2}{|l|}{ Male } & \multicolumn{2}{|c|}{ Female } \\
\hline & $e_{0}$ & $e_{0}^{L}$ & $e_{0}$ & $e_{0}^{L}$ & $e_{0}$ & $e_{0}^{L}$ & $\overline{e_{0}}$ & $e_{0}^{L}$ & $e_{0}$ & $e_{0}^{L}$ & $e_{0}$ & $e_{0}^{L}$ \\
\hline Belarus & 71.2 & 0.4 & 66.2 & 0.4 & 75.8 & 0.3 & 74.1 & 0.2 & 69.0 & 0.3 & 78.9 & 0.1 \\
\hline Belgium & 76.2 & 0.4 & 72.7 & 0.3 & 79.6 & 0.3 & 81.8 & 0.7 & 79.2 & 0.7 & 84.3 & 0.7 \\
\hline Belize & 72.2 & 1.6 & 70.5 & 1.7 & 74.0 & 1.5 & 74.7 & 1.3 & 71.4 & 1.3 & 78.4 & 1.4 \\
\hline Benin & 56.2 & 4.0 & 54.1 & 4.2 & 58.5 & 3.8 & 64.8 & 2.6 & 62.8 & 2.7 & 66.9 & 2.5 \\
\hline Bermuda & 74.1 & 0.4 & 69.7 & 0.3 & 78.8 & 0.4 & 82.1 & 0.5 & 77.3 & 0.4 & 87.4 & 0.6 \\
\hline Bhutan & 61.5 & 2.7 & 61.6 & 2.9 & 61.4 & 2.6 & 75.0 & 0.9 & 73.0 & 0.9 & 77.4 & 1.0 \\
\hline Bolivia & 61.0 & 4.2 & 59.8 & 4.3 & 62.2 & 4.1 & 73.2 & 1.5 & 71.7 & 1.5 & 74.7 & 1.5 \\
\hline Bosnia and Herzegovina & 74.0 & 0.4 & 70.8 & 0.4 & 77.1 & 0.4 & 77.0 & 0.2 & 74.5 & 0.2 & 79.4 & 0.2 \\
\hline Botswana & 63.8 & 2.3 & 58.9 & 2.5 & 69.3 & 1.8 & 69.2 & 1.5 & 67.1 & 1.6 & 71.1 & 1.4 \\
\hline Brazil & 68.2 & 1.5 & 64.4 & 1.5 & 72.2 & 1.4 & 76.2 & 1.2 & 72.5 & 1.1 & 79.9 & 1.3 \\
\hline Brunei & 70.5 & 0.7 & 69.0 & 0.8 & 72.5 & 0.6 & 75.7 & 1.0 & 73.5 & 1.0 & 78.2 & 1.0 \\
\hline Bulgaria & 71.8 & 0.7 & 68.3 & 0.8 & 75.8 & 0.7 & 75.0 & 0.3 & 71.4 & 0.3 & 78.8 & 0.2 \\
\hline Burkina Fas & 51.3 & 3.9 & 49.6 & 3.9 & 53.0 & 3.9 & 61.8 & 3.0 & 59.1 & 3.3 & 64.6 & 2.8 \\
\hline Burundi & 49.2 & 4.1 & 47.3 & 4.6 & 51.1 & 3.6 & 61.9 & 4.3 & 60.1 & 4.6 & 63.9 & 3.8 \\
\hline Cambodia & 57.9 & 4.5 & 55.6 & 4.6 & 60.0 & 4.5 & 70.0 & 2.2 & 66.8 & 2.2 & 73.0 & 2.1 \\
\hline Cameroon & 57.3 & 3.4 & 55.9 & 3.6 & 58.8 & 3.2 & 63.7 & 2.6 & 61.7 & 2.8 & 65.8 & 2.3 \\
\hline Canada & 77.6 & 0.4 & 74.2 & 0.4 & 81.1 & 0.5 & 82.5 & 0.5 & 80.5 & 0.5 & 84.5 & 0.5 \\
\hline Cape Verde & 70.9 & 2.3 & 66.7 & 2.1 & 74.5 & 2.5 & 75.8 & 1.8 & 72.3 & 1.7 & 79.4 & 1.7 \\
\hline Central African Republic & 47.9 & 4.7 & 45.2 & 4.8 & 50.8 & 4.5 & 49.4 & 4.5 & 46.7 & 4.6 & 52.5 & 4.2 \\
\hline Chad & 52.7 & 4.5 & 51.3 & 4.5 & 54.0 & 4.6 & 60.1 & 3.8 & 58.8 & 3.9 & 61.7 & 3.6 \\
\hline Chile & 73.4 & 1.4 & 70.1 & 1.5 & 76.7 & 1.3 & 80.0 & 0.7 & 77.4 & 0.6 & 82.5 & 0.7 \\
\hline China & 68.7 & 1.7 & 67.0 & 1.6 & 70.6 & 1.7 & 77.5 & 0.3 & 74.9 & 0.3 & 80.5 & 0.3 \\
\hline
\end{tabular}




\begin{tabular}{|c|c|c|c|c|c|c|c|c|c|c|c|c|}
\hline \multirow[t]{3}{*}{ Country/territory } & \multicolumn{6}{|c|}{1990} & \multicolumn{6}{|l|}{2017} \\
\hline & \multicolumn{2}{|c|}{$\begin{array}{l}\text { Both } \\
\text { genders }\end{array}$} & \multicolumn{2}{|l|}{ Male } & \multicolumn{2}{|c|}{ Female } & \multicolumn{2}{|c|}{$\begin{array}{l}\text { Both } \\
\text { genders }\end{array}$} & \multicolumn{2}{|l|}{ Male } & \multicolumn{2}{|c|}{ Female } \\
\hline & $e_{0}$ & $e_{0}^{L}$ & $e_{0}$ & $e_{0}^{L}$ & $e_{0}$ & $e_{0}^{L}$ & $e_{0}$ & $e_{0}^{L}$ & $e_{0}$ & $e_{0}^{L}$ & $e_{0}$ & $e_{0}^{L}$ \\
\hline Colombia & 71.9 & 0.9 & 68.6 & 1.0 & 75.3 & 0.9 & 82.0 & 0.7 & 79.2 & 0.8 & 84.8 & 0.7 \\
\hline Comoros & 58.3 & 3.4 & 57.0 & 3.6 & 59.7 & 3.1 & 69.4 & 2.7 & 67.8 & 2.9 & 70.8 & 2.4 \\
\hline Congo & 53.6 & 3.4 & 51.2 & 3.8 & 56.0 & 2.9 & 62.9 & 2.2 & 62.9 & 2.5 & 63.0 & 2.0 \\
\hline Costa Rica & 77.0 & 0.7 & 74.7 & 0.7 & 79.5 & 0.7 & 80.2 & 0.4 & 76.6 & 0.4 & 84.0 & 0.4 \\
\hline Cote d'Ivoire & 55.5 & 3.3 & 52.9 & 3.5 & 58.6 & 3.0 & 62.9 & 2.8 & 60.6 & 3.0 & 65.7 & 2.6 \\
\hline Croatia & 72.7 & 0.3 & 68.8 & 0.4 & 76.5 & 0.2 & 78.8 & 0.1 & 75.6 & 0.2 & 82.0 & 0.1 \\
\hline Cuba & 75.2 & 0.6 & 73.2 & 0.6 & 77.4 & 0.6 & 78.8 & 0.8 & 76.4 & 0.7 & 81.3 & 0.9 \\
\hline Cyprus & 76.3 & 0.3 & 73.7 & 0.3 & 79.0 & 0.4 & 82.9 & 0.4 & 78.9 & 0.3 & 87.3 & 0.5 \\
\hline Czech Republic & 71.5 & 0.2 & 67.5 & 0.2 & 75.6 & 0.2 & 79.3 & 0.4 & 76.5 & 0.4 & 82.1 & 0.3 \\
\hline Democratic Republic of the Congo & 53.8 & 4.3 & 51.8 & 4.3 & 55.9 & 4.2 & 62.0 & 3.6 & 60.0 & 3.7 & 64.0 & 3.5 \\
\hline Denmark & 75.1 & 0.3 & 72.2 & 0.3 & 78.0 & 0.4 & 80.9 & 0.6 & 79.1 & 0.5 & 82.8 & 0.6 \\
\hline Djibouti & 61.5 & 3.1 & 60.6 & 3.4 & 62.6 & 2.7 & 68.5 & 2.5 & 67.2 & 2.7 & 70.1 & 2.1 \\
\hline Dominica & 73.2 & 0.7 & 70.7 & 0.8 & 75.6 & 0.7 & 72.6 & 0.9 & 70.4 & 0.9 & 75.2 & 0.8 \\
\hline Dominican Republic & 72.3 & 1.5 & 69.9 & 1.5 & 74.7 & 1.4 & 73.7 & 0.8 & 70.1 & 0.7 & 77.8 & 0.8 \\
\hline Ecuador & 72.5 & 2.3 & 70.1 & 2.2 & 75.0 & 2.3 & 76.9 & 1.1 & 74.8 & 1.1 & 79.0 & 1.1 \\
\hline Egypt & 63.5 & 2.4 & 61.7 & 2.2 & 65.8 & 2.5 & 70.6 & 0.7 & 67.9 & 0.7 & 74.3 & 0.7 \\
\hline El Salvador & 69.5 & 1.4 & 65.0 & 1.3 & 74.0 & 1.4 & 74.1 & 1.0 & 69.2 & 1.0 & 78.6 & 1.1 \\
\hline Equatorial Guinea & 48.8 & 5.3 & 46.4 & 5.7 & 51.3 & 4.9 & 66.3 & 1.8 & 65.1 & 1.9 & 67.3 & 1.6 \\
\hline Eritrea & 34.4 & 2.6 & 29.2 & 2.2 & 41.7 & 2.9 & 61.4 & 4.1 & 58.1 & 4.7 & 64.7 & 3.4 \\
\hline Estonia & 70.1 & 0.3 & 64.8 & 0.4 & 75.1 & 0.2 & 78.5 & 0.3 & 73.9 & 0.3 & 82.7 & 0.2 \\
\hline Ethiopia & 48.4 & 5.3 & 46.6 & 5.6 & 50.3 & 5.0 & 68.9 & 3.1 & 66.9 & 3.3 & 71.2 & 2.8 \\
\hline Federated States of Micronesia & 63.6 & 1.6 & 61.8 & 1.6 & 65.7 & 1.6 & 67.2 & 0.8 & 65.0 & 0.8 & 69.5 & 0.8 \\
\hline Fiji & 67.5 & 1.1 & 65.3 & 1.1 & 70.0 & 1.1 & 68.1 & 0.8 & 65.9 & 0.8 & 70.5 & 0.8 \\
\hline Finland & 75.4 & 0.5 & 71.1 & 0.5 & 79.5 & 0.5 & 81.8 & 0.2 & 78.9 & 0.2 & 84.6 & 0.2 \\
\hline France & 77.3 & 0.4 & 73.1 & 0.4 & 81.5 & 0.4 & 83.5 & 0.5 & 80.3 & 0.5 & 86.5 & 0.6 \\
\hline Gabon & 60.3 & 3.2 & 56.7 & 3.6 & 64.4 & 2.6 & 68.0 & 2.1 & 64.5 & 2.4 & 71.9 & 1.7 \\
\hline Georgia & 69.9 & 1.4 & 65.7 & 1.6 & 73.8 & 1.2 & 72.6 & 0.3 & 68.3 & 0.4 & 77.0 & 0.2 \\
\hline Germany & 75.7 & 0.2 & 72.2 & 0.2 & 78.9 & 0.2 & 81.1 & 0.3 & 78.8 & 0.4 & 83.4 & 0.3 \\
\hline Ghana & 59.6 & 3.7 & 58.2 & 4.4 & 61.1 & 2.9 & 66.0 & 2.6 & 63.0 & 3.4 & 68.9 & 1.6 \\
\hline Greece & 78.0 & 0.3 & 74.9 & 0.2 & 81.2 & 0.3 & 81.6 & 0.5 & 78.9 & 0.4 & 84.5 & 0.5 \\
\hline Greenland & 65.1 & 0.7 & 61.9 & 0.6 & 69.1 & 0.7 & 73.8 & 0.6 & 71.0 & 0.5 & 77.6 & 0.6 \\
\hline Grenada & 69.6 & 0.9 & 67.3 & 0.9 & 71.8 & 1.0 & 74.8 & 1.1 & 74.7 & 1.2 & 75.5 & 1.0 \\
\hline Guam & 74.1 & 0.8 & 71.0 & 0.7 & 77.7 & 0.9 & 73.6 & 0.7 & 70.6 & 0.7 & 77.2 & 0.8 \\
\hline Guatemala & 62.8 & 3.6 & 60.3 & 3.6 & 65.5 & 3.7 & 73.3 & 2.1 & 69.5 & 2.0 & 77.2 & 2.2 \\
\hline Guinea & 51.3 & 5.3 & 51.1 & 5.5 & 51.5 & 5.2 & 60.8 & 3.3 & 59.5 & 3.6 & 62.2 & 3.0 \\
\hline Guinea-Bissau & 48.5 & 3.8 & 45.4 & 3.9 & 51.8 & 3.6 & 59.8 & 2.7 & 57.2 & 2.9 & 62.4 & 2.4 \\
\hline Guyana & 66.1 & 1.0 & 63.0 & 1.0 & 69.6 & 0.9 & 69.5 & 0.9 & 66.9 & 1.0 & 72.4 & 0.8 \\
\hline Haiti & 54.7 & 2.6 & 54.1 & 2.7 & 55.4 & 2.5 & 64.9 & 1.4 & 63.8 & 1.5 & 66.0 & 1.3 \\
\hline Honduras & 69.6 & 1.3 & 67.3 & 1.3 & 71.9 & 1.2 & 74.5 & 0.5 & 73.9 & 0.6 & 75.1 & 0.4 \\
\hline Hungary & 69.5 & 0.3 & 65.2 & 0.3 & 74.0 & 0.2 & 77.0 & 0.1 & 73.3 & 0.1 & 80.5 & 0.1 \\
\hline
\end{tabular}




\begin{tabular}{|c|c|c|c|c|c|c|c|c|c|c|c|c|}
\hline \multirow[t]{3}{*}{ Country/territory } & \multicolumn{6}{|l|}{1990} & \multicolumn{6}{|l|}{2017} \\
\hline & \multicolumn{2}{|c|}{$\begin{array}{l}\text { Both } \\
\text { genders }\end{array}$} & \multicolumn{2}{|l|}{ Male } & \multicolumn{2}{|c|}{ Female } & \multicolumn{2}{|c|}{$\begin{array}{l}\text { Both } \\
\text { genders }\end{array}$} & \multicolumn{2}{|l|}{ Male } & \multicolumn{2}{|c|}{ Female } \\
\hline & $e_{0}$ & $e_{0}^{L}$ & $e_{0}$ & $e_{0}^{L}$ & $e_{0}$ & $e_{0}^{L}$ & $e_{0}$ & $e_{0}^{L}$ & $e_{0}$ & $e_{0}^{L}$ & $e_{0}$ & $e_{0}^{L}$ \\
\hline Iceland & 78.0 & 0.6 & 75.6 & 0.5 & 80.3 & 0.8 & 83.2 & 0.6 & 80.0 & 0.5 & 86.8 & 0.8 \\
\hline India & 59.9 & 3.3 & 59.2 & 3.3 & 60.7 & 3.3 & 69.2 & 1.7 & 68.0 & 1.7 & 70.4 & 1.7 \\
\hline Indonesia & 64.2 & 3.3 & 62.7 & 3.7 & 65.8 & 2.8 & 71.5 & 1.2 & 69.2 & 1.3 & 74.0 & 1.0 \\
\hline Iran & 68.3 & 0.7 & 66.0 & 0.7 & 70.9 & 0.7 & 77.6 & 0.4 & 75.7 & 0.4 & 79.5 & 0.4 \\
\hline Iraq & 66.0 & 0.8 & 64.5 & 0.9 & 67.6 & 0.8 & 78.9 & 0.5 & 76.8 & 0.5 & 81.3 & 0.5 \\
\hline Ireland & 74.9 & 0.6 & 72.3 & 0.5 & 77.7 & 0.7 & 82.4 & 0.6 & 80.5 & 0.5 & 84.2 & 0.7 \\
\hline Israel & 78.0 & 0.4 & 76.3 & 0.4 & 79.7 & 0.4 & 83.4 & 0.7 & 81.7 & 0.7 & 85.0 & 0.7 \\
\hline Italy & 77.4 & 0.2 & 73.9 & 0.2 & 80.9 & 0.2 & 83.7 & 0.3 & 81.3 & 0.3 & 85.9 & 0.3 \\
\hline Jamaica & 75.4 & 0.6 & 73.9 & 0.6 & 76.8 & 0.6 & 74.6 & 0.4 & 72.2 & 0.4 & 77.2 & 0.4 \\
\hline Japan & 79.9 & 1.1 & 76.5 & 1.1 & 83.3 & 1.0 & 85.3 & 1.3 & 81.9 & 1.3 & 88.8 & 1.2 \\
\hline Jordan & 71.5 & 0.8 & 71.1 & 0.9 & 72.1 & 0.8 & 79.8 & 0.6 & 78.2 & 0.6 & 81.8 & 0.6 \\
\hline Kazakhstan & 68.5 & 1.3 & 63.5 & 1.4 & 73.3 & 1.1 & 71.9 & 0.6 & 67.3 & 0.7 & 76.4 & 0.4 \\
\hline Kenya & 62.4 & 2.8 & 61.1 & 3.1 & 63.7 & 2.5 & 66.1 & 2.5 & 63.3 & 2.7 & 69.2 & 2.2 \\
\hline Kiribati & 58.4 & 2.3 & 55.6 & 2.5 & 61.3 & 2.1 & 62.6 & 1.6 & 58.8 & 1.7 & 66.5 & 1.4 \\
\hline Kuwait & 76.9 & 1.1 & 76.1 & 1.2 & 78.4 & 1.1 & 79.7 & 0.9 & 77.3 & 0.9 & 82.2 & 0.9 \\
\hline Kyrgyzstan & 66.3 & 2.2 & 61.9 & 2.3 & 70.6 & 2.1 & 73.1 & 0.6 & 69.2 & 0.7 & 77.0 & 0.5 \\
\hline Laos & 52.4 & 5.1 & 50.1 & 5.4 & 54.8 & 4.6 & 67.6 & 2.1 & 65.0 & 2.3 & 70.5 & 1.9 \\
\hline Latvia & 70.0 & 0.3 & 64.7 & 0.4 & 74.9 & 0.2 & 75.4 & 0.3 & 70.2 & 0.4 & 80.2 & 0.2 \\
\hline Lebanon & 70.4 & 0.5 & 67.3 & 0.4 & 73.8 & 0.5 & 78.0 & 0.3 & 75.9 & 0.3 & 79.9 & 0.3 \\
\hline Lesotho & 60.7 & 3.2 & 56.4 & 3.6 & 65.6 & 2.6 & 55.3 & 2.9 & 51.1 & 3.6 & 59.8 & 1.9 \\
\hline Liberia & 46.1 & 4.6 & 43.8 & 4.6 & 48.5 & 4.6 & 64.9 & 2.4 & 64.3 & 2.6 & 65.6 & 2.3 \\
\hline Libya & 72.2 & 0.6 & 70.9 & 0.6 & 73.8 & 0.6 & 73.4 & 0.4 & 71.6 & 0.4 & 75.4 & 0.4 \\
\hline Lithuania & 71.5 & 0.3 & 66.5 & 0.4 & 76.3 & 0.2 & 75.2 & 0.4 & 69.7 & 0.5 & 80.6 & 0.3 \\
\hline Luxembourg & 75.6 & 0.3 & 71.9 & 0.2 & 79.3 & 0.3 & 82.0 & 0.4 & 80.7 & 0.5 & 83.3 & 0.4 \\
\hline Macedonia & 71.9 & 0.6 & 69.6 & 0.6 & 74.5 & 0.6 & 77.7 & 0.2 & 73.9 & 0.2 & 82.9 & 0.2 \\
\hline Madagascar & 55.4 & 3.3 & 53.9 & 3.6 & 56.9 & 3.0 & 63.5 & 2.3 & 62.3 & 2.4 & 64.7 & 2.1 \\
\hline Malawi & 48.4 & 2.6 & 46.5 & 2.6 & 50.4 & 2.6 & 63.6 & 2.8 & 59.7 & 3.0 & 67.6 & 2.4 \\
\hline Malaysia & 71.4 & 1.4 & 69.2 & 1.5 & 73.8 & 1.3 & 75.0 & 2.3 & 72.9 & 2.3 & 77.4 & 2.3 \\
\hline Maldives & 66.3 & 1.1 & 66.8 & 1.2 & 65.7 & 0.9 & 82.8 & 0.6 & 81.0 & 0.5 & 85.1 & 0.6 \\
\hline Mali & 48.2 & 2.9 & 48.0 & 3.1 & 48.3 & 2.7 & 61.8 & 1.7 & 60.8 & 1.8 & 62.9 & 1.6 \\
\hline Malta & 76.8 & 0.4 & 74.4 & 0.4 & 79.2 & 0.4 & 81.5 & 0.6 & 79.3 & 0.5 & 83.7 & 0.6 \\
\hline Marshall Islands & 62.8 & 1.4 & 59.9 & 1.4 & 66.3 & 1.4 & 64.6 & 1.0 & 62.6 & 0.9 & 67.0 & 1.0 \\
\hline Mauritania & 59.6 & 2.7 & 59.1 & 2.9 & 60.2 & 2.6 & 70.9 & 2.0 & 70.5 & 2.1 & 71.4 & 1.9 \\
\hline Mauritius & 70.2 & 0.7 & 66.4 & 0.7 & 74.4 & 0.7 & 75.0 & 0.5 & 71.7 & 0.5 & 78.4 & 0.5 \\
\hline Mexico & 71.8 & 1.3 & 68.9 & 1.4 & 74.7 & 1.3 & 76.1 & 0.6 & 73.0 & 0.6 & 79.1 & 0.5 \\
\hline Moldova & 67.9 & 0.9 & 64.3 & 1.0 & 71.4 & 0.7 & 73.2 & 0.7 & 68.5 & 0.9 & 77.9 & 0.4 \\
\hline
\end{tabular}




\begin{tabular}{|c|c|c|c|c|c|c|c|c|c|c|c|c|}
\hline \multirow[t]{3}{*}{ Country/territory } & \multicolumn{6}{|l|}{1990} & \multicolumn{6}{|l|}{2017} \\
\hline & \multicolumn{2}{|c|}{$\begin{array}{l}\text { Both } \\
\text { genders }\end{array}$} & \multicolumn{2}{|l|}{ Male } & \multicolumn{2}{|c|}{ Female } & \multicolumn{2}{|c|}{$\begin{array}{l}\text { Both } \\
\text { genders }\end{array}$} & \multicolumn{2}{|l|}{ Male } & \multicolumn{2}{|c|}{ Female } \\
\hline & $e_{0}$ & $e_{0}^{L}$ & $e_{0}$ & $e_{0}^{L}$ & $e_{0}$ & $e_{0}^{L}$ & $e_{0}$ & $e_{0}^{L}$ & $e_{0}$ & $e_{0}^{L}$ & $e_{0}$ & $e_{0}^{L}$ \\
\hline Mongolia & 61.3 & 3.7 & 58.8 & 3.7 & 64.1 & 3.6 & 69.2 & 0.8 & 64.7 & 0.9 & 74.1 & 0.7 \\
\hline Montenegro & 74.5 & 0.3 & 71.3 & 0.3 & 77.7 & 0.2 & 76.6 & 0.1 & 74.2 & 0.2 & 79.1 & 0.1 \\
\hline Morocco & 66.5 & 1.9 & 67.0 & 2.0 & 66.1 & 1.8 & 73.8 & 0.7 & 73.1 & 0.8 & 74.6 & 0.7 \\
\hline Mozambique & 49.7 & 3.8 & 47.4 & 4.1 & 52.1 & 3.5 & 58.4 & 2.9 & 54.8 & 3.2 & 62.2 & 2.5 \\
\hline Myanmar & 55.7 & 4.6 & 52.9 & 4.5 & 58.7 & 4.6 & 68.7 & 1.6 & 65.0 & 1.6 & 72.4 & 1.6 \\
\hline Namibia & 61.9 & 2.9 & 58.3 & 3.1 & 65.7 & 2.6 & 66.7 & 2.3 & 62.4 & 2.6 & 71.1 & 1.7 \\
\hline Nepal & 57.9 & 3.7 & 57.4 & 3.4 & 58.5 & 3.9 & 71.2 & 1.3 & 68.9 & 1.1 & 73.7 & 1.4 \\
\hline Netherlands & 77.2 & 0.3 & 73.8 & 0.2 & 80.5 & 0.4 & 81.8 & 0.5 & 80.2 & 0.5 & 83.3 & 0.5 \\
\hline New Zealand & 75.6 & 0.5 & 72.7 & 0.4 & 78.5 & 0.5 & 82.1 & 0.3 & 80.1 & 0.3 & 84.0 & 0.3 \\
\hline Nicaragua & 72.7 & 1.7 & 70.5 & 1.8 & 74.9 & 1.6 & 80.4 & 0.7 & 79.7 & 0.9 & 81.4 & 0.6 \\
\hline Niger & 46.4 & 5.3 & 45.6 & 5.6 & 47.3 & 5.1 & 63.0 & 3.1 & 61.8 & 3.2 & 64.3 & 2.9 \\
\hline Nigeria & 54.1 & 5.5 & 52.3 & 6.0 & 56.0 & 4.9 & 64.4 & 3.1 & 62.7 & 3.4 & 66.0 & 2.8 \\
\hline North Korea & 72.0 & 0.9 & 68.7 & 0.9 & 74.6 & 0.9 & 72.0 & 0.8 & 68.6 & 0.8 & 75.1 & 0.7 \\
\hline Northern Mariana Islands & 74.5 & 0.8 & 73.5 & 1.0 & 76.0 & 0.7 & 76.5 & 0.7 & 73.7 & 0.7 & 79.9 & 0.7 \\
\hline Norway & 76.8 & 0.6 & 73.4 & 0.5 & 80.2 & 0.7 & 82.4 & 0.6 & 80.6 & 0.5 & 84.1 & 0.6 \\
\hline Oman & 69.8 & 1.0 & 67.7 & 0.9 & 72.6 & 1.1 & 78.1 & 0.7 & 76.7 & 0.8 & 80.2 & 0.7 \\
\hline Pakistan & 60.6 & 2.5 & 60.6 & 2.4 & 60.5 & 2.5 & 66.1 & 1.2 & 65.7 & 1.3 & 66.6 & 1.2 \\
\hline Palestine & 70.8 & 0.8 & 69.2 & 0.9 & 72.3 & 0.8 & 77.5 & 0.6 & 77.8 & 0.7 & 77.7 & 0.5 \\
\hline Panama & 76.4 & 0.9 & 74.2 & 1.0 & 78.7 & 0.9 & 80.1 & 1.1 & 77.8 & 1.1 & 82.6 & 1.0 \\
\hline Papua New Guinea & 54.8 & 2.2 & 52.4 & 2.3 & 57.7 & 1.9 & 59.0 & 1.4 & 56.8 & 1.5 & 61.7 & 1.2 \\
\hline Paraguay & 74.5 & 1.1 & 72.3 & 1.2 & 76.7 & 1.1 & 76.6 & 0.8 & 73.8 & 0.8 & 79.6 & 0.8 \\
\hline Peru & 70.3 & 4.4 & 68.1 & 4.4 & 72.6 & 4.3 & 81.6 & 2.7 & 79.9 & 2.7 & 83.4 & 2.7 \\
\hline Philippines & 67.7 & 4.6 & 64.6 & 4.8 & 71.2 & 4.3 & 69.7 & 2.3 & 66.6 & 2.4 & 73.0 & 2.2 \\
\hline Poland & 71.3 & 0.4 & 66.8 & 0.5 & 76.0 & 0.3 & 78.4 & 0.4 & 74.3 & 0.5 & 82.4 & 0.4 \\
\hline Portugal & 74.2 & 0.5 & 70.7 & 0.5 & 77.7 & 0.4 & 81.9 & 0.8 & 78.9 & 0.9 & 84.8 & 0.8 \\
\hline Puerto Rico & 74.5 & 0.8 & 70.2 & 0.8 & 79.0 & 0.8 & 78.9 & 0.8 & 75.0 & 0.7 & 82.8 & 0.8 \\
\hline Qatar & 70.8 & 0.4 & 70.1 & 0.4 & 72.0 & 0.3 & 79.9 & 0.5 & 79.2 & 0.5 & 81.5 & 0.5 \\
\hline Romania & 70.1 & 1.2 & 66.9 & 1.4 & 73.4 & 1.0 & 75.4 & 0.6 & 71.6 & 0.7 & 79.3 & 0.5 \\
\hline Russian Federation & 69.7 & 0.5 & 64.2 & 0.6 & 74.8 & 0.3 & 72.3 & 0.5 & 67.0 & 0.7 & 77.4 & 0.3 \\
\hline Rwanda & 49.7 & 5.3 & 47.7 & 6.0 & 51.7 & 4.6 & 68.7 & 3.0 & 65.8 & 3.2 & 71.2 & 2.6 \\
\hline Saint Lucia & 70.5 & 0.7 & 67.8 & 0.7 & 73.3 & 0.7 & 75.4 & 0.7 & 73.1 & 0.7 & 77.9 & 0.7 \\
\hline Saint Vincent and the Grenadines & 71.2 & 0.8 & 69.5 & 0.9 & 72.9 & 0.7 & 73.3 & 0.8 & 70.7 & 0.8 & 76.4 & 0.9 \\
\hline Samoa & 70.8 & 1.2 & 68.2 & 1.2 & 73.9 & 1.1 & 72.9 & 0.7 & 71.5 & 0.8 & 74.4 & 0.7 \\
\hline Sao Tome and Principe & 64.2 & 3.3 & 62.5 & 3.4 & 65.8 & 3.1 & 69.9 & 2.2 & 68.0 & 2.3 & 71.8 & 2.1 \\
\hline Saudi Arabia & 71.2 & 1.1 & 69.8 & 0.9 & 73.2 & 1.3 & 76.5 & 0.7 & 74.5 & 0.5 & 80.0 & 1.0 \\
\hline Senegal & 58.2 & 3.8 & 56.3 & 3.9 & 60.3 & 3.8 & 68.2 & 2.6 & 66.3 & 2.6 & 70.3 & 2.6 \\
\hline Serbia & 70.6 & 0.3 & 67.1 & 0.4 & 74.5 & 0.3 & 75.3 & 0.2 & 73.7 & 0.2 & 77.2 & 0.1 \\
\hline
\end{tabular}




\begin{tabular}{|c|c|c|c|c|c|c|c|c|c|c|c|c|}
\hline \multirow[t]{3}{*}{ Country/territory } & \multicolumn{6}{|l|}{1990} & \multicolumn{6}{|l|}{2017} \\
\hline & \multicolumn{2}{|c|}{$\begin{array}{l}\text { Both } \\
\text { genders }\end{array}$} & \multicolumn{2}{|l|}{ Male } & \multicolumn{2}{|c|}{ Female } & \multicolumn{2}{|c|}{$\begin{array}{l}\text { Both } \\
\text { genders }\end{array}$} & \multicolumn{2}{|l|}{ Male } & \multicolumn{2}{|c|}{ Female } \\
\hline & $e_{0}$ & $e_{0}^{L}$ & $e_{0}$ & $e_{0}^{L}$ & $e_{0}$ & $e_{0}^{L}$ & $e_{0}$ & $e_{0}^{L}$ & $e_{0}$ & $e_{0}^{L}$ & $e_{0}$ & $e_{0}^{L}$ \\
\hline Seychelles & 70.5 & 1.7 & 66.0 & 1.6 & 75.8 & 1.7 & 73.6 & 1.5 & 70.1 & 1.5 & 77.7 & 1.4 \\
\hline Sierra Leone & 49.3 & 5.2 & 47.4 & 5.3 & 51.4 & 5.0 & 60.2 & 3.2 & 59.4 & 3.6 & 61.2 & 2.9 \\
\hline Singapore & 76.5 & 1.3 & 73.9 & 1.1 & 79.2 & 1.4 & 84.8 & 2.3 & 82.1 & 2.2 & 87.4 & 2.4 \\
\hline Slovakia & 71.0 & 0.7 & 66.7 & 0.7 & 75.6 & 0.7 & 77.5 & 0.4 & 74.2 & 0.5 & 80.8 & 0.4 \\
\hline Slovenia & 74.1 & 0.3 & 69.8 & 0.3 & 78.2 & 0.3 & 81.7 & 0.4 & 78.4 & 0.4 & 85.1 & 0.4 \\
\hline Solomon Islands & 61.7 & 2.8 & 60.1 & 2.8 & 63.6 & 2.7 & 65.9 & 2.1 & 64.3 & 2.1 & 67.6 & 2.0 \\
\hline Somalia & 47.8 & 3.5 & 45.8 & 3.7 & 50.0 & 3.2 & 59.5 & 3.7 & 57.6 & 4.1 & 61.7 & 3.3 \\
\hline South Africa & 65.3 & 3.6 & 61.4 & 3.6 & 69.2 & 3.4 & 66.7 & 2.0 & 63.1 & 2.1 & 70.2 & 1.7 \\
\hline South Korea & 72.3 & 0.7 & 68.0 & 0.7 & 76.7 & 0.6 & 84.1 & 0.9 & 80.4 & 0.9 & 87.6 & 0.9 \\
\hline South Sudan & 52.0 & 3.3 & 50.4 & 3.4 & 54.1 & 3.2 & 58.3 & 3.9 & 56.1 & 4.1 & 61.0 & 3.5 \\
\hline Spain & 77.3 & 0.4 & 73.6 & 0.4 & 81.0 & 0.3 & 83.8 & 0.4 & 80.7 & 0.4 & 86.7 & 0.4 \\
\hline Sri Lanka & 69.5 & 1.1 & 65.4 & 1.1 & 74.7 & 1.1 & 77.9 & 0.7 & 74.0 & 0.7 & 81.9 & 0.6 \\
\hline Sudan & 58.0 & 1.7 & 57.0 & 1.6 & 59.0 & 1.7 & 70.1 & 0.7 & 68.6 & 0.8 & 71.9 & 0.7 \\
\hline Suriname & 68.5 & 0.8 & 66.0 & 0.9 & 71.2 & 0.8 & 72.3 & 0.8 & 69.0 & 0.8 & 75.8 & 0.8 \\
\hline Swaziland & 62.1 & 3.0 & 57.9 & 3.4 & 66.6 & 2.3 & 60.0 & 2.4 & 55.2 & 2.8 & 65.2 & 1.7 \\
\hline Sweden & 78.0 & 0.5 & 75.1 & 0.4 & 81.0 & 0.5 & 82.6 & 0.4 & 81.1 & 0.4 & 84.1 & 0.4 \\
\hline Switzerlar & 78.2 & 0.5 & 74.6 & 0.4 & 81.8 & 0.5 & 84.7 & 0.4 & 82.9 & 0.4 & 86.4 & 0.4 \\
\hline Syria & 69.6 & 0.6 & 67.7 & 0.7 & 71.9 & 0.5 & 69.7 & 0.3 & 64.9 & 0.3 & 76.3 & 0.4 \\
\hline Taiwan (Province of China) & 74.9 & 0.9 & 72.5 & 1.1 & 77.8 & 0.7 & 80.4 & 1.2 & 76.9 & 1.2 & 84.3 & 1.1 \\
\hline Tajikistan & 67.9 & 3.1 & 65.0 & 3.1 & 71.0 & 3.2 & 71.3 & 1.7 & 68.3 & 1.7 & 74.9 & 1.6 \\
\hline Tanzania & 55.2 & 3.6 & 53.5 & 3.6 & 56.9 & 3.5 & 67.1 & 3.2 & 64.9 & 3.4 & 69.5 & 2.9 \\
\hline Thailand & 71.1 & 1.6 & 67.6 & 1.7 & 74.8 & 1.5 & 79.5 & 1.9 & 75.0 & 1.7 & 84.1 & 2.0 \\
\hline The Bahamas & 71.5 & 1.0 & 67.7 & 1.0 & 75.4 & 1.0 & 74.0 & 0.8 & 71.1 & 0.8 & 76.9 & 0.8 \\
\hline The Gambia & 60.2 & 3.6 & 58.0 & 3.7 & 62.8 & 3.3 & 65.8 & 2.4 & 63.8 & 2.5 & 67.9 & 2.3 \\
\hline Timor-Leste & 59.9 & 4.2 & 59.4 & 4.5 & 60.4 & 3.8 & 71.2 & 1.5 & 69.1 & 1.5 & 73.7 & 1.4 \\
\hline Togo & 57.9 & 3.7 & 56.3 & 3.7 & 59.5 & 3.6 & 64.8 & 2.4 & 61.8 & 2.5 & 67.7 & 2.3 \\
\hline Tonga & 70.0 & 1.0 & 68.3 & 1.1 & 71.9 & 1.0 & 71.6 & 0.8 & 68.7 & 0.8 & 74.8 & 0.8 \\
\hline Trinidad ar & 70.0 & 0.7 & 67.6 & 0.7 & 72.7 & 0.7 & 74.7 & 0.5 & 71.4 & 0.5 & 78.2 & 0.5 \\
\hline Tunisia & 72.2 & 0.7 & 70.6 & 0.7 & 74.0 & 0.7 & 77.9 & 0.3 & 75.6 & 0.3 & 80.5 & 0.3 \\
\hline Turkey & 69.1 & 1.5 & 66.0 & 1.5 & 72.6 & 1.5 & 80.7 & 0.5 & 75.4 & 0.4 & 87.5 & 0.6 \\
\hline Turkmenistan & 66.1 & 2.7 & 62.6 & 2.8 & 69.5 & 2.5 & 70.6 & 1.0 & 67.1 & 1.1 & 74.2 & 0.8 \\
\hline Uganda & 47.4 & 2.0 & 44.2 & 1.8 & 50.9 & 2.1 & 66.1 & 2.8 & 62.6 & 2.9 & 69.8 & 2.5 \\
\hline Ukraine & 70.5 & 0.4 & 65.6 & 0.4 & 75.0 & 0.3 & 70.5 & 0.4 & 64.7 & 0.6 & 76.5 & 0.2 \\
\hline United Arab Emirates & 71.1 & 0.8 & 70.1 & 0.7 & 72.9 & 0.9 & 72.8 & 0.6 & 71.3 & 0.6 & 76.2 & 0.7 \\
\hline United Kingdom & 75.9 & 0.6 & 73.0 & 0.5 & 78.7 & 0.7 & 81.2 & 0.8 & 79.5 & 0.7 & 82.8 & 0.8 \\
\hline United States & 75.9 & 0.5 & 72.3 & 0.4 & 79.5 & 0.5 & 78.7 & 0.5 & 76.3 & 0.4 & 81.2 & 0.5 \\
\hline Uruguay & 73.3 & 0.5 & 69.5 & 0.5 & 77.2 & 0.5 & 77.3 & 0.6 & 73.7 & 0.6 & 80.8 & 0.7 \\
\hline Uzbekistan & 69.8 & 2.2 & 66.3 & 2.3 & 73.1 & 2.0 & 69.8 & 1.1 & 66.7 & 1.1 & 73.1 & 1.0 \\
\hline Vanuatu & 62.5 & 1.4 & 59.9 & 1.4 & 65.9 & 1.4 & 64.8 & 1.0 & 62.2 & 1.1 & 67.8 & 1.0 \\
\hline Venezuela & 72.4 & 1.0 & 69.4 & 1.0 & 75.5 & 1.0 & 75.8 & 0.6 & 71.5 & 0.6 & 80.3 & 0.6 \\
\hline
\end{tabular}




\begin{tabular}{|c|c|c|c|c|c|c|c|c|c|c|c|c|}
\hline \multirow[t]{3}{*}{ Country/territory } & \multicolumn{6}{|l|}{1990} & \multicolumn{6}{|l|}{2017} \\
\hline & \multicolumn{2}{|c|}{$\begin{array}{l}\text { Both } \\
\text { genders }\end{array}$} & \multicolumn{2}{|l|}{ Male } & \multicolumn{2}{|l|}{ Female } & \multicolumn{2}{|c|}{$\begin{array}{l}\text { Both } \\
\text { genders }\end{array}$} & \multicolumn{2}{|l|}{ Male } & \multicolumn{2}{|c|}{ Female } \\
\hline & $e_{0}$ & $e_{0}^{L}$ & $e_{0}$ & $e_{0}^{L}$ & $e_{0}$ & $e_{0}^{L}$ & $e_{0}$ & $e_{0}^{L}$ & $e_{0}$ & $e_{0}^{L}$ & $e_{0}$ & $e_{0}^{L}$ \\
\hline Vietnam & 69.1 & 2.1 & 65.1 & 2.1 & 73.1 & 1.9 & 74.8 & 0.9 & 70.1 & 0.9 & 79.7 & 0.8 \\
\hline Virgin Islands, U.S & 72.7 & 0.4 & 69.1 & 0.4 & 76.5 & 0.5 & 74.1 & 0.4 & 69.6 & 0.3 & 79.1 & 0.4 \\
\hline Yemen & 58.4 & 1.7 & 57.4 & 1.6 & 59.6 & 1.8 & 68.3 & 0.7 & 66.2 & 0.6 & 70.7 & 0.7 \\
\hline Zambia & 50.7 & 3.5 & 49.3 & 3.6 & 52.1 & 3.3 & 63.6 & 3.0 & 60.7 & 3.3 & 66.8 & 2.5 \\
\hline Zimbabwe & 61.2 & 2.9 & 57.7 & 3.1 & 65.3 & 2.5 & 61.7 & 4.1 & 58.5 & 5.1 & 64.7 & 3.0 \\
\hline
\end{tabular}

Data source: Global Burden of Disease Study (2017)

\section{Appendix F Rankings of country and territory for loss of LE due to RID at birth and the changes in loss of LE due to RID at birth during the period 1990-2017}

\begin{tabular}{|c|c|c|c|c|c|c|c|c|c|c|c|}
\hline \multirow[t]{3}{*}{ Rank } & \multicolumn{2}{|l|}{1990} & \multirow[t]{3}{*}{ Rank } & \multirow{2}{*}{\multicolumn{2}{|c|}{$\begin{array}{l}2017 \\
\text { Highest loss of } \\
\text { life expectancy } \\
\text { due RID }\left(e_{0,2017}^{L}\right)\end{array}$}} & \multirow[t]{3}{*}{ Rank } & \multirow{2}{*}{\multicolumn{2}{|c|}{$\begin{array}{l}\frac{1990-2017}{\text { Largest increase }} \\
\text { in loss of life } \\
\text { expectancy } \\
\text { due RID } \\
\left(e_{0,2017}^{L}-e_{0,1990}^{L}\right)\end{array}$}} & \multirow[t]{3}{*}{ Rank } & \multirow{2}{*}{\multicolumn{2}{|c|}{$\begin{array}{l}1990-2017 \\
\text { Largest } \\
\text { increase in loss } \\
\text { of life expec- } \\
\text { tancy due RID } \\
\text { in proportion } \\
{\left[\left(\left(1\left(\varepsilon_{0,2017}^{L}-e_{0.1990}^{L}\right) / e_{0.1990}^{L}\right]\right.\right.}\end{array}$}} \\
\hline & \multicolumn{2}{|c|}{$\begin{array}{l}\text { Highest loss of } \\
\text { life expectancy } \\
\text { due } \operatorname{RID}\left(e_{0,1990}^{L}\right)\end{array}$} & & & & & & & & & \\
\hline & $\begin{array}{l}\text { Country/ } \\
\text { territory }\end{array}$ & Years & & $\begin{array}{l}\text { Country/ } \\
\text { territory }\end{array}$ & Years & & $\begin{array}{l}\text { Country/ } \\
\text { territory }\end{array}$ & Years & & $\begin{array}{l}\text { Country/ } \\
\text { territory }\end{array}$ & $\%$ \\
\hline 1 & Nigeria & 5.5 & 1 & $\begin{array}{l}\text { Central } \\
\text { African } \\
\text { Repub- } \\
\text { lic }\end{array}$ & 4.5 & 1 & Eritrea & 1.5 & 1 & Argentina & 111.3 \\
\hline 2 & Niger & 5.3 & 2 & Burundi & 4.3 & 2 & $\begin{array}{c}\text { Zimba- } \\
\text { bwe }\end{array}$ & 1.2 & 2 & Belgium & 96.1 \\
\hline 3 & Rwanda & 5.3 & 3 & $\begin{array}{c}\text { Zimba- } \\
\text { bwe }\end{array}$ & 4.1 & 3 & $\begin{array}{c}\text { Singa- } \\
\text { pore }\end{array}$ & 1.0 & 3 & Greece & 85.4 \\
\hline 4 & Ethiopia & 5.3 & 4 & Eritrea & 4.1 & 4 & Malaysia & 0.9 & 4 & Israel & 84.3 \\
\hline 5 & Guinea & 5.3 & 5 & $\begin{array}{l}\text { South } \\
\text { Sudan }\end{array}$ & 3.9 & 5 & Uganda & 0.8 & 5 & $\begin{array}{l}\text { Singa- } \\
\text { pore }\end{array}$ & 79.6 \\
\hline 6 & $\begin{array}{c}\text { Equatorial } \\
\text { Guinea }\end{array}$ & 5.3 & 6 & Chad & 3.8 & 6 & Argentina & 0.7 & 6 & Australia & 77.7 \\
\hline 7 & $\begin{array}{l}\text { Sierra } \\
\text { Leone }\end{array}$ & 5.2 & 7 & Somalia & 3.7 & 7 & $\begin{array}{l}\text { South } \\
\text { Sudan }\end{array}$ & 0.5 & 7 & Portugal & 76.5 \\
\hline 8 & Laos & 5.1 & 8 & $\begin{array}{l}\text { Demo- } \\
\text { cratic } \\
\text { Repub- } \\
\text { lic of } \\
\text { the } \\
\text { Congo }\end{array}$ & 3.6 & 8 & Portugal & 0.4 & 8 & Denmark & 71.7 \\
\hline
\end{tabular}




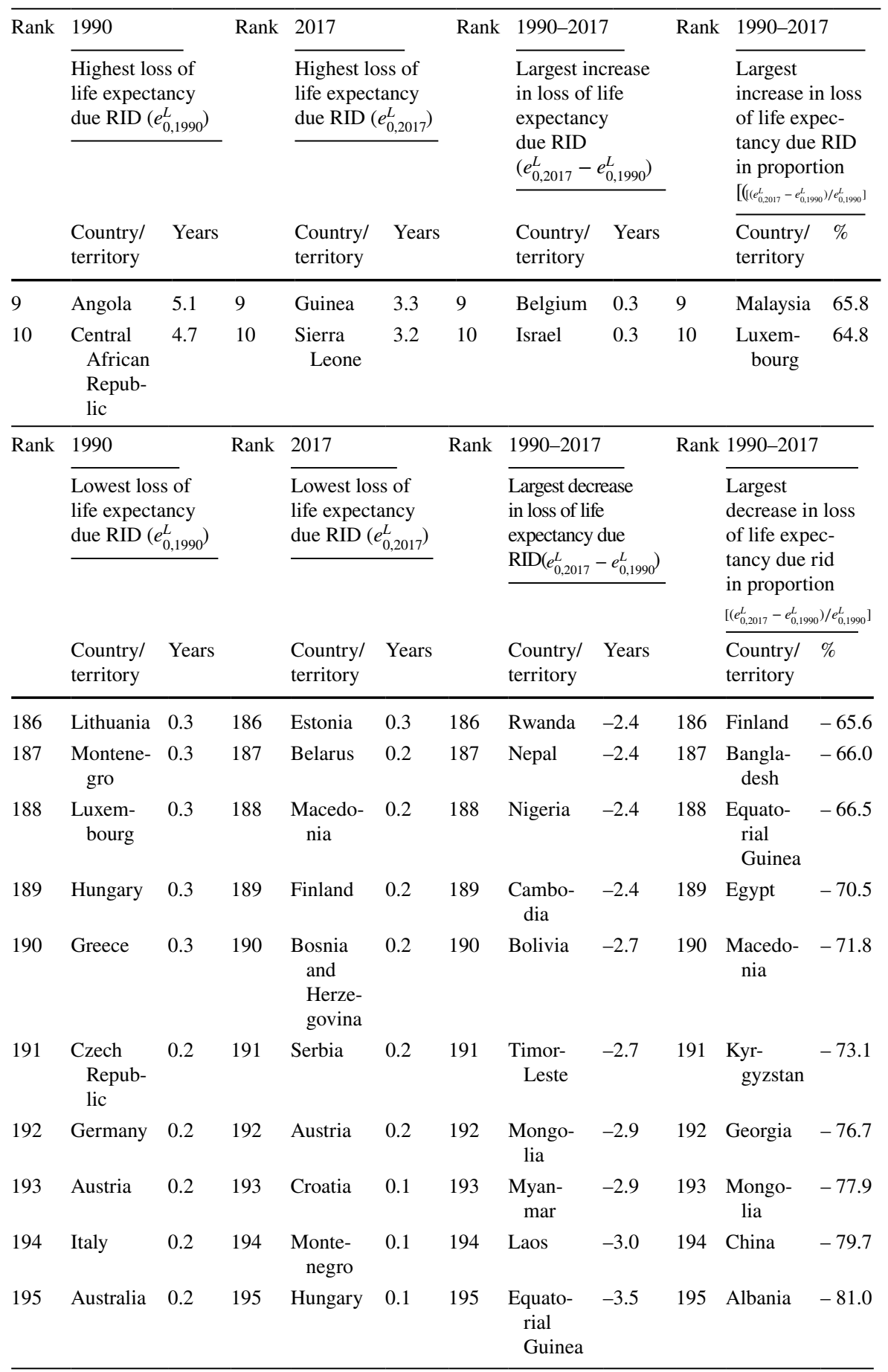

Source: Global Burden of Disease Study (2017) 


\section{Declarations}

Conflict of interest The authors declare that they have no conflict of interest.

Ethical approval The study was based on a publicly accessible database so no ethical approval was required for this study.

\section{References}

Abubakar, I., Tillmann, T., \& Banerjee, A. (2015). Global, regional, and national age-sex specific allcause and cause-specific mortality for 240 causes of death, 1990-2013: A systematic analysis for the Global Burden of Disease Study 2013. Lancet, 385(9963), 117-171.

Ahsan Karar, Z., Alam, N., \& Kim Streatfield, P. (2009). Epidemiological transition in rural Bangladesh, 1986-2006. Global Health Action, 2(1), 1904-1913.

Albala, C., \& Vio, F. (1995). Epidemiological transition in Latin America: The case of Chile. Public Health, 109(6), 431-442.

Alexandrino, A. S., Santos, R., Melo, C., \& Bastos, J. M. (2016). Risk factors for respiratory infections among children attending day care centres. Family Practice, 33(2), 161-166.

Armstrong, G. L., Conn, L. A., \& Pinner, R. W. (1999). Trends in infectious disease mortality in the United States during the 20th century. JAMA, 281(1), 61-66.

Aungkulanon, S., Kusreesakul, K., Kunnathum, J., \& Bundhamcharoen, K. (2013). Decreasing the burden of infectious disease in Thailand. The Lancet, 381, S11.

Australian Department of Health. (2020). Coronavirus (COVID-19) current situation and case numbers. Retrieved October 25, 2020, from https://www.health.gov.au/news/health-alerts/novelcoronavirus-2019-ncov-health-alert/coronavirus-covid-19-current-situation-and-case-numbers

Bedford, J., Enria, D., Giesecke, J., Heymann, D. L., Ihekweazu, C., Kobinger, G., et al. (2020). COVID-19: Towards controlling of a pandemic. The Lancet, 395(10229), 1015-1018.

Booth, C. M., Matukas, L. M., Tomlinson, G. A., Rachlis, A. R., Rose, D. B., Dwosh, H. A., et al. (2003). Clinical features and short-term outcomes of 144 patients with SARS in the greater Toronto area. JAMA, 289(21), 2801-2809.

Byng-Maddick, R., \& Noursadeghi, M. (2016). Does tuberculosis threaten our ageing populations? BMC Infectious Diseases, 16(1), 1-5.

Casoni, G., Caramori, G., Papadopoulos, N., Johnston, S., \& Papi, A. (2003). Respiratory diseases in women: European respiratory monograph. European Respiratory Society.

Castelli, F., \& Sulis, G. (2017). Migration and infectious diseases. Clinical Microbiology and Infection, 23(5), 283-289.

Centers for Disease Control and Prevention. (2018). Health, United States, 2018-Data Finder. Retrieved August 19, 2020, from https://www.cdc.gov/nchs/hus/contents2018.htm?search=Influ enza_and_pneumonia,.

Centers for Disease Control and Prevention. (2020). Coronavirus Disease 2019 Case SurveillanceUnited States, January 22-May 30, 2020. Retrieved August 13, 2020, from https://www.cdc.gov/ $\mathrm{mmwr} /$ volumes/69/wr/mm6924e2.htm\#suggestedcitation

Centers for Disease Control Prevention. (1999a). Control of infectious diseases. Morbidity and Mortality Weekly Report, 48(29), 621.

Centers for Disease Control Prevention. (1999b). Outbreak of influenza A infection among travelers-Alaska and the Yukon Territory, May-June 1999. Morbidity and Mortality Weekly Report, $48(25), 545$.

Chapman, K. R., Tashkin, D. P., \& Pye, D. J. (2001). Gender bias in the diagnosis of COPD. Chest, 119(6), 1691-1695.

Chen, H., Chen, G., Zheng, X., \& Guo, Y. (2019). Contribution of specific diseases and injuries to changes in health adjusted life expectancy in 187 countries from 1990 to 2013: Retrospective observational study. BMJ, 364, 1969-1980.

Chiang, C. L. (1979). Life table and mortality analysis. World Health Organization. 
Chinese Center for Disease Control and Prevention. (2020). The epidemiological characteristics of an outbreak of 2019 novel coronavirus diseases (COVID-19) in China. Chinese Journal of Epidemiology, 41(2), 145-151.

Cohen, M. L. (2000). Changing patterns of infectious disease. Nature, 406(6797), 762-767.

Corrêa, R., d. A., José, B. P. d. S., Malta, D. C., Passos, V. M. d. A., França, E. B., Teixeira, R. A., , et al. (2017). Burden of disease by lower respiratory tract infections in Brazil, 1990 to 2015: Estimates of the Global Burden of Disease 2015 study. Revista Brasileira De Epidemiologia, 20, $171-181$.

Dhar, S., Shastri, S. R., \& Lenora, R. A. (1976). Aging and the respiratory system. Medical Clinics of North America, 60(6), 1121-1139.

Dudel, C., Riffe, T., Acosta, E., van Raalte, A., Strozza, C., \& Myrskylä, M. (2020). Monitoring trends and differences in COVID-19 case-fatality rates using decomposition methods: Contributions of age structure and age-specific fatality. PLOS ONE, 15(9), e0238904.

Dyer, C. (2012). The interaction of ageing and lung disease. Chronic Respiratory Disease, 9(1), 63-67.

Fauci, A. S. (2001). Infectious diseases: Considerations for the 21 st century. Clinical Infectious Diseases, 32(5), 675-685.

Gannon, C. J., Pasquale, M., Tracy, J. K., McCarter, R. J., \& Napolitano, L. M. (2004). Male gender is associated with increased risk for postinjury pneumonia. Shock, 21(5), 410-414.

Gardner, I. D. (1980). The effect of aging on susceptibility to infection. Reviews of Infectious Diseases, 2(5), 801-810.

Garibaldi, R. (1999). Residential care and the elderly: The burden of infection. Journal of Hospital Infection, 43, S9-S18.

Garibaldi, R. A., Brodine, S., \& Matsumiya, S. (1981). Infections among patients in nursing homes: Policies, prevalence, and problems. New England Journal of Medicine, 305(13), 731-735.

Gavazzi, G., Herrmann, F., \& Krause, K.-H. (2004). Aging and infectious diseases in the developing world. Clinical Infectious Diseases, 39(1), 83-91.

Gavazzi, G., \& Krause, K.-H. (2002). Ageing and infection. The Lancet Infectious Diseases, 2(11), $659-666$.

GBD 2015 Eastern Mediterranean Region Lower Respiratory Infections Collaborators. (2018). Burden of lower respiratory infections in the Eastern Mediterranean Region between 1990 and 2015 : Findings from the Global Burden of Disease 2015 study. International Journal of Public Health, $63,97-108$.

Global Burden of Disease Study. (2017). Global Health Data Exchange. Retrieved 17 June, 2020, from http://ghdx.healthdata.org/gbd-results-tool

Habib, N. A., \& Behrens, R. H. (2000). Respiratory infections in the traveler. Current Opinion in Pulmonary Medicine, 6(3), 246-249.

Haq, K., \& McElhaney, J. E. (2014). Ageing and respiratory infections: The airway of ageing. Immunology Letters, 162(1), 323-328.

Hauser, A., Counotte, M. J., Margossian, C. C., Konstantinoudis, G., Low, N., Althaus, C. L., \& Riou, J. (2020). Estimation of SARS-CoV-2 mortality during the early stages of an epidemic: A modeling study in Hubei, China, and six regions in Europe. PLoS Medicine, 17(7), e1003189.

Health Minister of Spain. (2020). The 59th Updats for Coronavirus (COVID-19). Rtrieved June 19, 2020, from https://www.imedhospitales.com/coronavirus/assets/Actualizacion_59_COVID-19.pdf

High, K. P. (2002). Infection in an ageing world. The Lancet Infectious Diseases, 2(11), 655.

Hinman, A. R. (1998). Global progress in infectious disease control. Vaccine, 16(11-12), 1116-1121.

Holmen, T., Barrett-Connor, E., Clausen, J., Langhammer, A., Holmen, J., \& Bjermer, L. (2002). Gender differences in the impact of adolescent smoking on lung function and respiratory symptoms. The Nord-Trøndelag Health Study, Norway, 1995-1997. Respiratory Medicine, 96(10), 796-804.

Hutto, C., Ricks, R., Garvie, M., \& Pass, R. F. (1985). Epidemiology of cytomegalovirus infections in young children: day care vs. home care. Pediatric Infectious Disease, 4(2), 149-152.

Janssens, J.-P., Pache, J.-C., \& Nicod, L. (1999). Physiological changes in respiratory function associated with ageing. European Respiratory Journal, 13(1), 197-205.

Jin, J.-M., Bai, P., He, W., Wu, F., Liu, X.-F., Han, D.-M., et al. (2020). Gender differences in patients with COVID-19: Focus on severity and mortality. Frontiers in Public Health, 8, 152-157.

Keyfitz, N. (1977). What difference would it make if cancer were eradicated? An examination of the Taeuber paradox. Demography, 14(4), 411-418.

Kumate, J. (1997). Infectious diseases in the 21st century. Archives of Medical Research, 28(2), 155-161. 
Kyu, H. H., Abate, D., Abate, K. H., Abay, S. M., Abbafati, C., Abbasi, N., et al. (2018). Global, regional, and national disability-adjusted life-years (DALYs) for 359 diseases and injuries and healthy life expectancy (HALE) for 195 countries and territories, 1990-2017: A systematic analysis for the Global Burden of Disease Study 2017. The Lancet, 392(10159), 1859-1922.

Lalloo, U. G., \& Pillay, S. (2008). Managing tuberculosis and HIV in sub-Sahara Africa. Current HIV/ AIDS Reports, 5(3), 132-139.

Lee, V. J., Chiew, C. J., \& Khong, W. X. (2020). Interrupting transmission of COVID-19: lessons from containment efforts in Singapore. Journal of Travel Medicine, 27(3), taaa039.

Leibovici, L. (1995). Bacteraemia in the very old. Drugs \& Aging, 6(6), 456-464.

Liu, Q., Xu, K., Wang, X., \& Wang, W. (2020). From SARS to COVID-19: What lessons have we learned? Journal of Infection and Public Health, 13(11), 1611-1618.

Louhiala, P. J., Jaakkola, N., Ruotsalainen, R., \& Jaakkola, J. (1995). Form of day care and respiratory infections among Finnish children. American Journal of Public Health, 85(8_Pt_1), 1109-1112.

Lozano, R., Naghavi, M., Foreman, K., Lim, S., Shibuya, K., Aboyans, V., et al. (2012). Global and regional mortality from 235 causes of death for 20 age groups in 1990 and 2010: A systematic analysis for the Global Burden of Disease Study 2010. The Lancet, 380(9859), 2095-2128.

Mackenbach, J. (1993). The epidemiological transition in The Netherlands. Nederlands Tijdschrift Voor Geneeskunde, 137(3), 132-138.

MacPherson, D. W., Gushulak, B. D., \& Macdonald, L. (2007). Health and foreign policy: Influences of migration and population mobility. Bulletin of the World Health Organization, 85, 200-206.

Marston, B. J., Plouffe, J. F., File, T. M., Hackman, B. A., Salstrom, S.-J., Lipman, H. B., et al. (1997). Incidence of community-acquired pneumonia requiring hospitalization: Results of a population-based active surveillance study in Ohio. Archives of Internal Medicine, 157(15), 1709-1718.

Matheï, C., Niclaes, L., Suetens, C., Jans, B., \& Buntinx, F. (2007). Infections in residents of nursing homes. Infectious Disease Clinics of North America, 21(3), 761-772.

Mathers, C. D., Bernard, C., Iburg, K. M., Inoue, M., Ma Fat, D., Shibuya, K., et al. (2003). Global burden of disease in 2002: Data sources, methods and results (p. 54). World Health Organization.

McClelland, E. E., \& Smith, J. M. (2011). Gender specific differences in the immune response to infection. Archivum Immunologiae Et Therapiae Experimentalis, 59(3), 203-213.

McKeown, R. E. (2009). The epidemiologic transition: changing patterns of mortality and population dynamics. American Journal of Lifestyle Medicine, 3(1_suppl), S19-S26.

Michaud, C. (2009). Global burden of infectious diseases. Encyclopedia of Microbiology, 444-454.

Momtazmanesh, S., Ochs, H. D., Uddin, L. Q., Perc, M., Routes, J. M., Vieira, D. N., et al. (2020). All together to Fight COVID-19. The American Journal of Tropical Medicine and Hygiene, 102(6), 1181-1183.

Moran, K. R., \& Del Valle, S. Y. (2016). A meta-analysis of the association between gender and protective behaviors in response to respiratory epidemics and pandemics. PLOS ONE, 11(10), e0164541.

Murray, C. J., Barber, R. M., Foreman, K. J., Ozgoren, A. A., Abd-Allah, F., Abera, S. F., et al. (2015). Global, regional, and national disability-adjusted life years (DALYs) for 306 diseases and injuries and healthy life expectancy (HALE) for 188 countries, 1990-2013: Quantifying the epidemiological transition. The Lancet, 386(10009), 2145-2191.

Murray, C. J., Vos, T., Lozano, R., Naghavi, M., Flaxman, A. D., Michaud, C., et al. (2012). Disabilityadjusted life years (DALYs) for 291 diseases and injuries in 21 regions, 1990-2010: A systematic analysis for the Global Burden of Disease Study 2010. The Lancet, 380(9859), 2197-2223.

Nair, H., Brooks, W. A., Katz, M., Roca, A., Berkley, J. A., Madhi, S. A., et al. (2011). Global burden of respiratory infections due to seasonal influenza in young children: A systematic review and meta-analysis. The Lancet, 378(9807), 1917-1930.

Nair, H., Nokes, D. J., Gessner, B. D., Dherani, M., Madhi, S. A., Singleton, R. J., et al. (2010). Global burden of acute lower respiratory infections due to respiratory syncytial virus in young children: A systematic review and meta-analysis. The Lancet, 375(9725), 1545-1555.

Nathell, L., Malmberg, P., Lundbäck, B., \& Nygren, А. (2000). Impact of occupation on respiratory disease. Scandinavian Journal of Work, Environment \& Health, 26(5), 382-389.

Omran, A. R. (1971). The epidemiologic transition: A theory of the epidemiology of population change. The Milbank Quarterly, 83(4), 731-757.

Omran, A. R. (1983). The epidemiologic transition theory. A preliminary update. Journal of Tropical Pediatrics, 29(6), 305-316.

Omran, A. R. (1998). The epidemiologic transition theory revisited thirty years later. World Health Statistics Quarterly, 51(2-4), 99-119. 
Onder, G., Rezza, G., \& Brusaferro, S. (2020). Case-fatality rate and characteristics of patients dying in relation to COVID-19 in Italy. JAMA, 323(18), 1775-1776.

Pavia, A. T. (2007). Germs on a plane: Aircraft, international travel, and the global spread of disease. The Journal of Infectious Diseases, 195(5), 621-622.

Pickering, L. K., Bartlett, A. V., \& Woodward, W. E. (1986). Acute infectious diarrhea among children in day care: Epidemiology and control. Clinical Infectious Diseases, 8(4), 539-547.

Ryan, E. T., Wilson, M. E., \& Kain, K. C. (2002). Illness after international travel. New England Journal of Medicine, 347(7), 505-516.

Santosa, A., Wall, S., Fottrell, E., Högberg, U., \& Byass, P. (2014). The development and experience of epidemiological transition theory over four decades: A systematic review. Global Health Action, 7(1), 23574.

Shi, T., Denouel, A., Tietjen, A. K., Campbell, I., Moran, E., Li, X., et al. (2020). Global disease burden estimates of respiratory syncytial virus-associated acute respiratory infection in older adults in 2015: a systematic review and meta-analysis. The Journal of Infectious Diseases, 222(Supplement_7), S577-S583.

Smallman-Raynor, M., \& Phillips, D. (1999). Late stages of epidemiological transition: Health status in the developed world. Health \& Place, 5(3), 209-222.

Smith, D. P. (1985). Formulae for cause-deleted life tables. Statistics in Medicine, 4(2), 155-162.

Sohrabi, C., Alsafi, Z., O’Neill, N., Khan, M., Kerwan, A., Al-Jabir, A., et al. (2020). World Health Organization declares global emergency: A review of the 2019 novel coronavirus (COVID-19). International Journal of Surgery, 76, 71-76.

Soneji, S., Beltrán-Sánchez, H., Yang, J., \& Mann, C. (2021). Population-level death rates from Novel Coronavirus (COVID-19) in South Korea. Asia Pacific Journal of Public Health, 33(2), 293-295.

Stevens, G., Dias, R. H., Thomas, K. J., Rivera, J. A., Carvalho, N., Barquera, S., et al. (2008). Characterizing the epidemiological transition in Mexico: national and subnational burden of diseases, injuries, and risk factors. PLoS Medicine, 5(6), e125.

Stevens, P. (2004). Diseases of poverty and the 10/90 gap. International Policy Network. Retrieved July 7 , 2020, from http://who.int/intellectualproperty/submissions/InternationalPolicyNetwork.pdf

Strausbaugh, L. J., Sukumar, S. R., Joseph, C. L., \& High, K. P. (2003). Infectious disease outbreaks in nursing homes: An unappreciated hazard for frail elderly persons. Clinical Infectious Diseases, 36(7), 870-876.

Troeger, C., Blacker, B., Khalil, I. A., Rao, P. C., Cao, J., Zimsen, S. R., et al. (2018). Estimates of the global, regional, and national morbidity, mortality, and aetiologies of lower respiratory infections in 195 countries, 1990-2016: A systematic analysis for the Global Burden of Disease Study 2016. The Lancet Infectious Diseases, 18(11), 1191-1210.

Troeger, C., Forouzanfar, M., Rao, P. C., Khalil, I., Brown, A., Swartz, S., et al. (2017). Estimates of the global, regional, and national morbidity, mortality, and aetiologies of lower respiratory tract infections in 195 countries: A systematic analysis for the Global Burden of Disease Study 2015. The Lancet Infectious Diseases, 17(11), 1133-1161.

Troeger, C. E., Blacker, B. F., Khalil, I. A., Zimsen, S. R., Albertson, S. B., Abate, D., et al. (2019). Mortality, morbidity, and hospitalisations due to influenza lower respiratory tract infections, 2017: An analysis for the Global Burden of Disease Study 2017. The Lancet Respiratory Medicine, 7(1), 69-89.

Troeger, C. E., Khalil, I. A., Blacker, B. F., Biehl, M. H., Albertson, S. B., Zimsen, S. R., et al. (2020). Quantifying risks and interventions that have affected the burden of lower respiratory infections among children younger than 5 years: An analysis for the Global Burden of Disease Study 2017. The Lancet Infectious Diseases, 20(1), 60-79.

Tsai, S. P., Lee, E. S., \& Hardy, R. J. (1978). The effect of a reduction in leading causes of death: Potential gains in life expectancy. American Journal of Public Health, 68(10), 966-971.

United Nations. (2019a). World Economic Situation And Prospects As Of Mid-2019. Retrieved September 23, 2020, from https://www.un.org/development/desa/dpad/publication/world-economic-situation-andprospects-as-of-mid2019/.

United Nations. (2019b). World Population Prospects 2019. Retrieved September 23, 2020, from https:// population.un.org/wpp/.

Wainwright, C. (2010). Acute viral bronchiolitis in children-a very common condition with few therapeutic options. Paediatric Respiratory Reviews, 11(1), 39-45.

Wang, H., Dwyer-Lindgren, L., Lofgren, K. T., Rajaratnam, J. K., Marcus, J. R., Levin-Rector, A., et al. (2012). Age-specific and sex-specific mortality in 187 countries, 1970-2010: A systematic analysis for the Global Burden of Disease Study 2010. The Lancet, 380(9859), 2071-2094.

World Health Organization. (2004). International statistical classification of diseases and related health problems (Vol. 1). World Health Organization. 
Wu, Y., Guo, W., Liu, H., Qi, B., Liang, K., Xu, H., et al. (2020). Clinical outcomes of 402 patients with COVID-2019 from a single center in Wuhan, China. Journal of Medical Virology, 92(11), 2751-2757.

Yamaya, M., Ohrui, T., Kubo, H., Ebihara, S., Arai, H., \& Sasaki, H. (2002). Prevention of respiratory infections in the elderly. Geriatrics \& Gerontology International, 2(3), 115-121.

Yoshikawa, T. T., \& Marrie, T. J. (2000). Community-acquired pneumonia in the elderly. Clinical Infectious Diseases, 31(4), 1066-1078.

Publisher's Note Springer Nature remains neutral with regard to jurisdictional claims in published maps and institutional affiliations.

\section{Authors and Affiliations}

\section{Guogui Huang ${ }^{1,2}$ - Fei Guo ${ }^{3}$}

Guogui Huang

guogui.huang@mq.edu.au

1 Centre for Workforce Futures, Macquarie Business School, Macquarie University, North Ryde, NSW 2109, Australia

2 Centre for Health Systems and Safety Research, Australia Institute of Health and Innovation, Macquarie University, North Ryde, NSW 2109, Australia

3 Department of Management, Macquarie Business School, Macquarie University, North Ryde, NSW 2109, Australia 